ISSN 1420-3049

www.mdpi.com/journal/molecules

Review

\title{
MAOS and Medicinal Chemistry: Some Important Examples from the Last Years
}

\section{Nailton M. Nascimento-Júnior ${ }^{1,2 *}$, Arthur E. Kümmerle ${ }^{3}$, Eliezer J. Barreiro ${ }^{1,2,4}$ and}

\section{Carlos A. M. Fraga ${ }^{1,2,4, *}$}

1 Laboratório de Avaliação e Síntese de substâncias Bioativas (LASSBio), Faculdade de Farmácia, Universidade Federal do Rio de Janeiro, PO Box 68023, Rio de Janeiro 21941-902, RJ, Brazil

2 Programa de Pós-Graduação em Química, Instituto de Química, Universidade Federal do Rio de Janeiro, Rio de Janeiro 21949-900, RJ, Brazil

3 Departamento de Química, Instituto de Ciências Exatas, Universidade Federal Rural do Rio de Janeiro, Seropédica 23890-000, RJ, Brazil

4 Programa de Pós-Graduação em Farmacologia e Química Medicinal, Instituto de Ciências Biomédicas, Universidade Federal do Rio de Janeiro, Rio de Janeiro 21941-902, RJ, Brazil

* Author to whom correspondence should be addressed; E-Mail: cmfraga@ccsdecania.ufrj.br; Tel.: +55-21-2562-6503; Fax: +55-21-2562-6478.

Received: 16 September 2011; in revised form: 17 October 2011 / Accepted: 26 October 2011 / Published: 7 November 2011

\begin{abstract}
This review aims to highlight microwave-assisted organic synthesis as applied to medicinal chemistry in the last years, showing some reactions performed under microwave irradiation for the synthesis of distinct structurally molecules of biological interest, divided into the following groups: antineoplastics, anti-inflammatory, antimicrobial agents, antivirals, agents for the treatment of neglected diseases and central nervous system-acting prototypes.
\end{abstract}

Keywords: microwave irradiation; medicinal chemistry; bioactive compounds; drug discovery 


\section{Introduction}

The first reports describing the use of microwave irradiation in organic synthesis were published in 1986 by Gedye et al. and Giguere et al. [1,2]. After commercial microwave equipment became available (in the mid-1990s) the application of microwaves in organic chemistry has increased significantly, specially because of its positive effects, reducing reaction time and increasing yields. Consequently, problems related with reproducibility, safety and controlled conditions as temperature, stirring and pressure were solved, contributing to the development of the area of microwave-assisted organic synthesis (MAOS) [3]. In addition, new conditions, strategies and technologies were incorporated to MAOS, for example: solvent-free synthesis, which is an example of an eco-friendly approach [4], aqueous media reactions [5], multicomponent reactions [6], combinatorial chemistry [7], continuous flow reactions, microreactor reactions [8] and large scale reactions [9], showing that the problem related with the small amount of products obtained for pharmaceutical industry application is, maybe, about to be solved.

In the context of medicinal chemistry, a large variety of biologically interesting scaffolds obtained using MAOS is described in literature: indoles [10], quinoxalines, pyrido[2,3-b]pyrazines, thieno[3,4- $b]$ pyrazines [11], quinazolines [12], [1,2,4]triazolo[4,3-a]pyridines [13], porphyrines [14], 1,2,4-triazoles [15], 1,2,4-oxadiazoles [16], $N$-acylhydrazones [17], the pyrazolo[4,3- $d$ ]pyrimidinone heteroaromatic subunit, present in the pharmaceutical drug sildenafil [18], etc.

The growth in the number of papers published in the medicinal chemistry area using microwave irradiation as a tool can be observed in the SCOPUS database [19] (Figure 1). We used the keyword "microwave" (in article title, abstract or keywords) and the main medicinal chemistry journals: "Journal of Medicinal Chemistry", "European Journal of Medicinal Chemistry", "Bioorganic and Medicinal Chemistry", "Bioorganic and Medicinal Chemistry Letters", "Molecules", "ChemMedChem", "Current Medicinal Chemistry", "Journal of Pharmaceutical Sciences" and "Mini-Reviews in Medicinal Chemistry". These results show the progressive increase in interest in the application of MAOS in drug discovery, as can be observed in the medicinal chemistry literature [20-22].

Figure 1. The number of papers published since the 2000th year (until August, 2011) in medicinal chemistry journals using the keyword "microwave" (www.scopus.com).

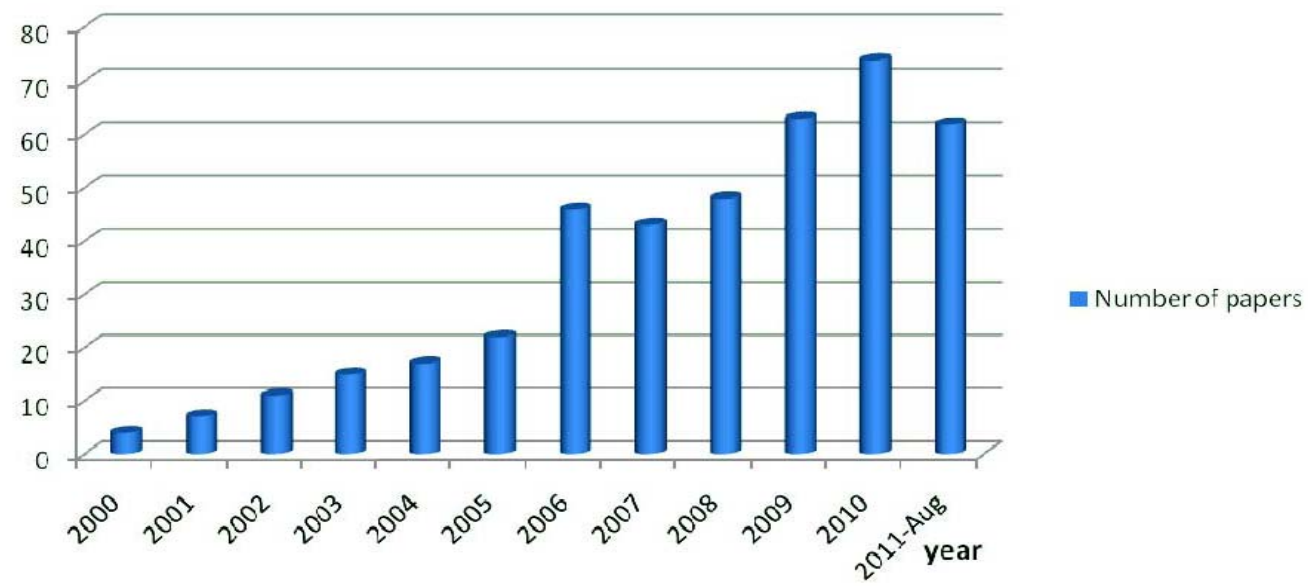


To illustrate the application of MAOS in medicinal chemistry, we have selected various examples of reactions and scaffolds of biological interest that can be obtained using microwave irradiation. For this purpose, these reactions were distributed according to therapeutic class into six areas: antineoplastics, anti-inflammatory, antimicrobial agents, antiviral, neglected diseases and central nervous system.

\section{Antineoplastics}

The pathophysiology of cancer is one in which a group of cells shows uncontrolled growth, tissue invasion, and sometimes metastasis. Neoplastic cells can be divided into benign, where the events of invasion and metastasis do not occur, and malignant. Cancer can affect individuals of all ages, but is most prevalent in older people, being responsible for the death of 7.9 million people worldwide in 2007 [23].

Several research groups have sought to use inhibitors of kinases as a way to combat cancer. Among these, one can cite the EGFR tyrosine kinase (endothelial growth factor receptor), VEGFR (vascular endothelial growth factor receptor) and FGFR (vascular endothelial fibroblast growth factor receptor) and Bcr-Abl (target action imatinib), the PI3K (phosphatidylinositol 3'quinase), the cyclin-dependent kinases (CDK) and serine-threonine kinases such as MAPK (mitogen-activated protein kinase) [24].

Within the universe of serine-threonine kinases, Lindsley et al. decided to explore the synthesis and structure activity relationship of new selective allosteric inhibitors of Akt, a protein kinase B (PKB) recently described [25], using microwave irradiation for the construction of a chemical library of quinoxalines and pyrazinones from 1,2-diketone intermediates [26].

The authors used 2,3-diphenylquinoxaline 1, a hit obtained by high throughput screening (HTS), and selective for isoforms 1 and 2, which are over expressed in several types of tumors, without action on PKA and PKC, as a prototype for the construction of its compounds (Figure 2).

Figure 2. Synthesis of allosteric Akt kinase inhibitors with antineoplastic activity.

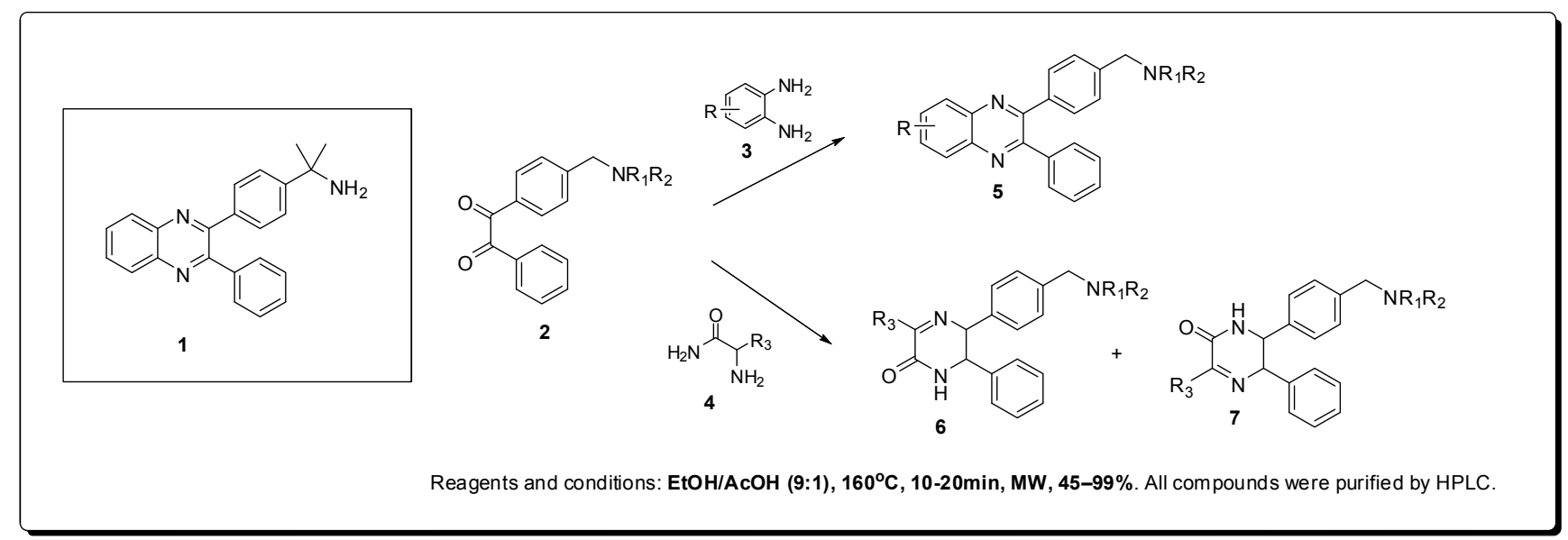

The use of microwave irradiation through a scientific microwave reactor, allowed the rapid preparation of a library containing approximately 250 chemical compounds through reactions of various 1,2-diketones 2 with 1,2-diaminobenzenes 3 or substituted $\alpha$-aminocarboxamides $\mathbf{4}$, using a 
solvent mixture of $\mathrm{EtOH} / \mathrm{AcOH}(9: 1)$ at $160{ }^{\circ} \mathrm{C}$ for $10-20 \mathrm{~min}$ in yields ranging from 45 to $99 \%$, after purification on preparative HPLC column.

The pharmacological evaluation of this chemolibrary demonstrated that several compounds were active on tumor cell lines, inhibiting allosterically the isoforms 1 and 2 of Akt, selectively, with potency in the nanomolar range. Moreover, compound 5a (Figure 3) stood out, being able to inhibit the in vivo phosphorylation of Akt.

Figure 3. The diphenylquinoxaline 1 (hit obtained by HTS) and compound 5a, compounds able to inhibit the in vivo phosphorylation of Akt.
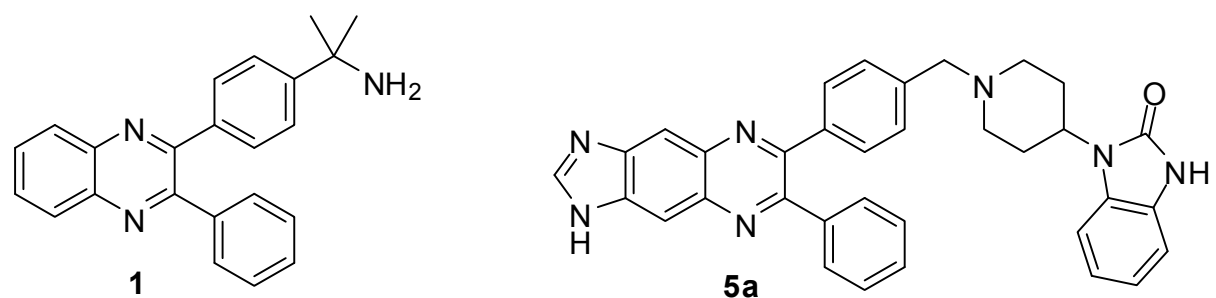

The PI3K-PKB-mTOR intracellular kinase signaling cascade is a major component in controlling cell proliferation and survival [27]. The misregulation of this pathway is primarily associated with the development of tumors in humans, in this case, leads to a superexpression of PKB, making it a target for therapeutic interventions of proven efficacy in animal models [28].

Drug design based on crystallographic data structure, using chimeras of PKA and PKA-PKB, led to the discovery of new pyrrolo[2,3- $d]$ pyridine compounds as selective inhibitors of PKB $\beta$, with potency in the nanomolar range and PKB/PKA selectivity values around 30 [29]. The final step used in the construction of these compounds passed through a nucleophilic aromatic substitution reaction $\left(\mathrm{S}_{\mathrm{N}} \mathrm{Ar}\right)$ of secondary amines $\mathbf{8}$ and $\mathbf{9}$ with functionalized pyrrolo[2,3-b]pyridine derivatives (Figure 4).

Figure 4. Microwave synthesis of pyrrolo[2,3- $d]$ pyridine inhibitors of PKB.<smiles>[R]c1ccc(C(N)C2CCNCC2)cc1</smiles>

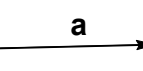<smiles>[R]c1ccc(C(N)C2CCN(c3ccnc4[nH]ccc34)CC2)cc1</smiles>

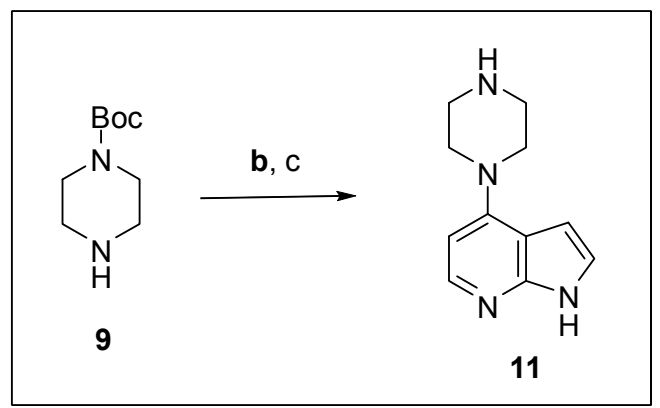

Reagents and conditions: (a) $N$-methyl-2-pyrrolidone (NMP) , MW, $155^{\circ} \mathrm{C}, 1 \mathrm{~h}$; (b) NMP, MW, $160^{\circ} \mathrm{C}, 1 \mathrm{~h}$; (c) $\mathrm{CF}_{3} \mathrm{CO}_{2} \mathrm{H}, \mathrm{CH}_{2} \mathrm{Cl}_{2}, 0^{\circ} \mathrm{C}$. 
The reactivity in this step is very low under conventional heating, requiring drastic heating and long reaction times, in consequence, this reaction does not occur when less reactive amines are used. Through the use of a scientific microwave reactor, Caldwell et al. developed a new $\mathrm{S}_{\mathrm{N}} \mathrm{Ar}$ methodology for halogenated purines which was then used in the synthesis of these PKB $\beta$ inhibitors [30].

Several recent studies have shown a correlation between cell cycle regulation and cancer. Thus, cell cycle inhibitors are being considered a tool for the management of cancer [31]. Notably, many groups have sought effective molecules that act on targets involved in phases $G_{0} / G_{1}$, such as cyclin D1, p53 and CdkIs for the control of inadequate cell proliferation [32].

In this context, a complete SAR study was performed for a group of $(R, S)$-6-substituted-7- or 9-(1,2,3,5-tetrahydro-4,1-benzoxazepine-3-yl)-7H or 9H-purines for their anticancer activity [33]. The designed compounds 12-15 (Figure 5) were obtained by the microwave-assisted Vorbrüggen one-pot condensation of the cyclic acetals $\mathbf{1 6}$ and $\mathbf{1 7}$ [34] and the commercially available purine bases 6-chloro-, 6-bromo- and 2,6-dichloropurines, using chlorotrimethylsilane (TMSCl), 1,1,1,3,3,3-hexamethyldisilazane (HMDS) and tin(IV) chloride as the Lewis acid in anhydrous acetonitrile in a scientific microwave reactor. Their antiproliferative activities on MCF-7 and MDA-MB-231 cancerous cell lines led to the discovery of an active enantiomeric mixture $(R S)$-2,6-dichloro-9-[1-( $p$-nitrobenzenesulfonyl)-1,2,3,5tetrahydro-4,1-benzoxazepin-3-yl]-9H-purine (12) that presented an $\mathrm{IC}_{50}$ of $0.166 \mu \mathrm{M}$ against the human cancerous cell line MDA-MB-231.

Figure 5. Preparation of the $O, N$-acetals anticancer derivatives 12-15.
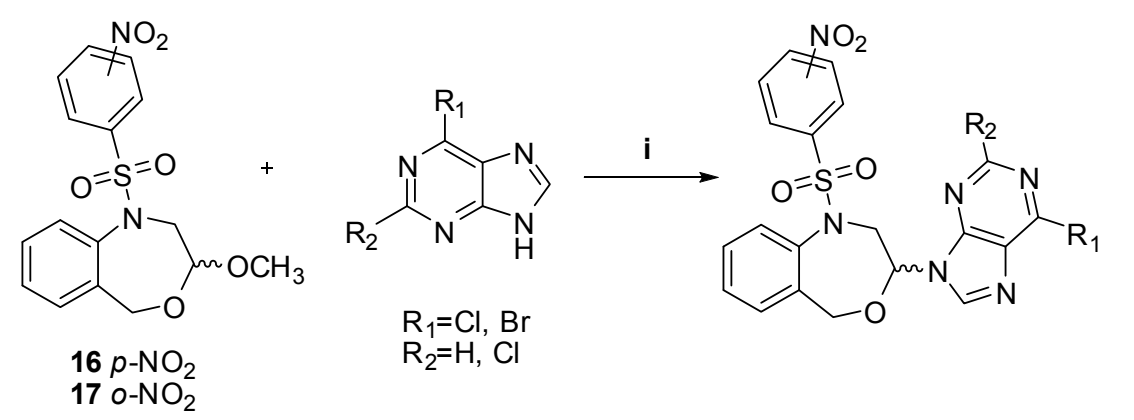

12 isomer: $p-\mathrm{NO}_{2}, \mathrm{R}_{1}=\mathrm{R}_{2}=\mathrm{Cl}$

13 isomer: $o-\mathrm{NO}_{2}, \mathrm{R}_{1}=\mathrm{R}_{2}=\mathrm{Cl}$

14 isomer: $p-\mathrm{NO}_{2}, \mathrm{R}_{1}=\mathrm{Br} \mathrm{R}_{2}=\mathrm{H}$

15 isomer: $\mathrm{o}-\mathrm{NO}_{2}, \mathrm{R}_{1}=\mathrm{Br} \mathrm{R}_{2}=\mathrm{H}$

$\mathrm{R}_{2}=\mathrm{H}, \mathrm{Cl}$

Reagents and conditions: i) purine, TMSCI, HMDS, $\mathrm{SnCl}_{4}\left(1 \mathrm{M}\right.$ solution in $\left.\mathrm{CH}_{2} \mathrm{Cl}_{2}\right), 140$ or $160^{\circ} \mathrm{C}$, microwave, 5 min

\section{Anti-Inflammatory}

The inflammatory process is a response to an aggression caused by an external agent and can be divided into acute and chronic inflammation, according to the time required to resolve it [35]. In this context, there are several targets for the treatment of inflammation and inhibition of pro-inflammatory cytokines, like the tumor necrosis factor alpha (TNF- $\alpha$ ) and interleukins (IL-6 and IL-1 $\beta$ ), that can be used for the treatment of rheumatoid arthritis, inflammatory intestinal diseases, medulla transplant-related rejection problems [36] and inflammatory diseases on the respiratory level [37].

Based on the anti-inflammatory effects of quinones obtained from natural products [38,39], Phutdhawong and co-workers have planned and synthesized a series of 1,6,7,8-tetrahydronaphtho[2,3- 
$d$ ]azepino[4,5-b]indole-9,14-diones 16 (Figure 6) with inhibitory effects related with the pro-inflammatory cytokine production [40].

Figure 6. Synthesis of azepinonaphthoquinones with anti-inflammatory activity.

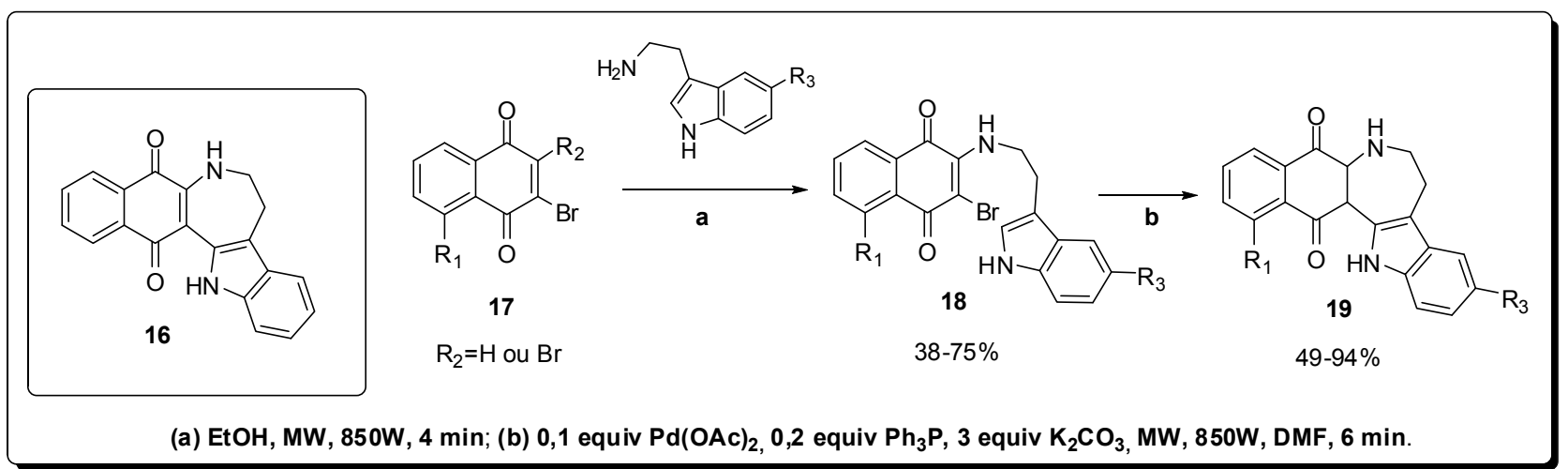

The synthetic route exploited to obtain the azepinonaphthoquinones 19 was based on the nucleophilic substitution reaction in bromonaphthoquinones 17 [41], followed by Pd-catalyzed intramolecular cyclization of 18, using a domestic microwave oven. The products were obtained after extremely short reaction times, in good yields and without formation of reduction side products in the cyclization step (Figure 6). These results were important for the construction of this new series of heterocyclic derivatives that was able to reduce the production of pro-inflammatory cytokines in vitro assays.

Another anti-inflammatory approach consists in the antagonism of CXCR3 chemokine receptors, that are expressed mainly in T-lymphocytes $\left(\mathrm{CD}^{+}\right.$and $\left.\mathrm{CD} 8^{+}\right)$, B-lymphocytes, natural killer cells and astrocytes $[42,43]$. The antagonism of CXCR3 receptors are important to treat rheumatoid arthritis $[44,45]$, multiple sclerosis, transplant rejection [46] and chronic obstructive pulmonary disease (COPD) [47]. For this propose, Knight and co-workers have described recently a series of 2-aminoquinolines 20 (Figure 7) with potent antagonist activity in CXCR3 and adequate physico-chemical properties, that have resulted in good bioavailability and in vivo activity [48].

Figure 7. Anti-inflammatory 2-aminoquinolines obtained using MAOS.

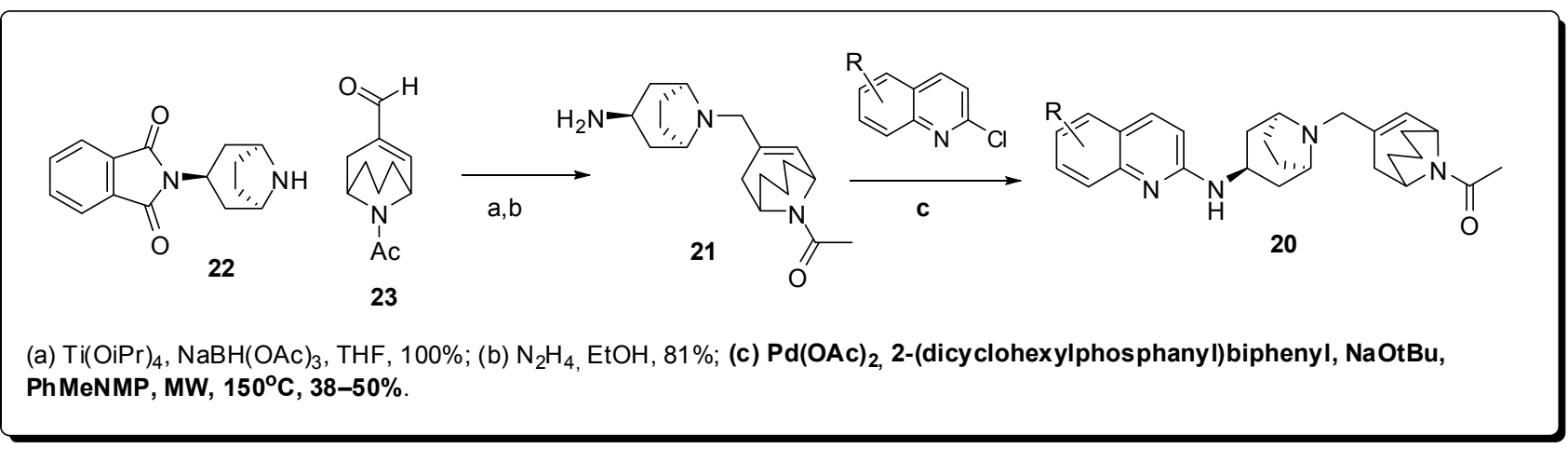

The aminotropanic derivative 21 used in the Knight work was obtained through the reductive amination between the amine 22 and the aldehyde 23, followed by hydrazinolysis. To obtain the derivatives 20, it was used a microwave-assisted amination reaction between $\mathbf{2 1}$ and the corresponding 
chloroquinolines, using 2-(dicyclohexylphosphanyl)biphenyl as ligand, resulting in the formation of the desired product $\mathbf{2 0}$ in moderate yields (38-50\%) [49].

\section{Antimicrobial Agents}

Since the antibacterial sulfonamide drugs were introduced into clinical practice in 1936 (the beginning of antimicrobial therapy) great advances have been achieved in the chemotherapy of infectious diseases. After World War II, important antimicrobial agents were found, e.g., penicillin, and nowadays this therapeutical class is composed by an expressive diversity of drugs. The recognition of replication mechanisms in bacteria, fungi or virus have helped in the rational development of compounds able to interfere with some key steps of vital cycle of these microorganisms [50]. In addition, the strategy of using genomic information for the identification and characterization of new biotargets has improved the discovery process of novel antimicrobial prototypes targeting resistant strains of different types of microorganisms [51].

The $N$-acylhydrazones and $N$-arylhydrazones classes are described in the literature as presenting antimicrobial, anticonvulsant, analgesic, anti-inflammatory, antitumoral, antiplatelet (antiaggregant), antineoplastic and other activities [52,53]. In this context, Ajani and co-workers have described MAOS of a series of 2-quinoxalinone-3-hydrazone derivatives expected to exhibit antimicrobial profile [54].

The condensation of the key-intermediate 3-hydrazinoquinoxalin-2(1H)-one (24) with the corresponding ketone derivatives, by using a scientific microwave reactor, has resulted in the formation of hydrazone derivatives $\mathbf{2 5 a}-\mathbf{p}$ in very short times (1-3 minutes) and excellent yields (55-99\%) (Figure 8) [54].

Figure 8. Synthesis of derivatives 25a-p.

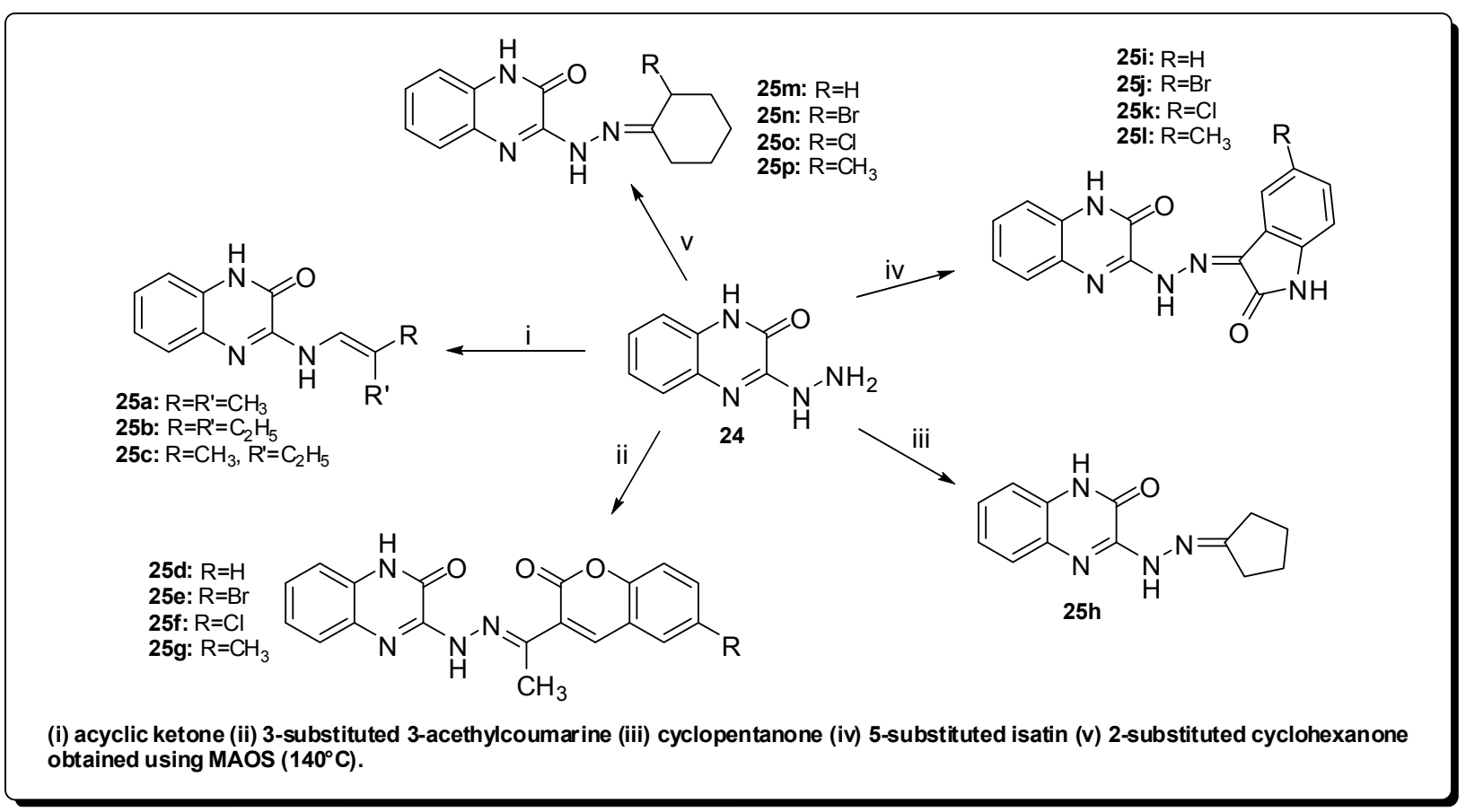

It was observed that $E$. coli and $K$. pneumoniae have developed resistance against streptomycin, while all the synthesized derivatives $\mathbf{2 5 a}-\mathbf{p}$ were active against these two microorganisms. The 
evidenced inhibition zone is from 10 to $32 \mathrm{~mm}$ and the derivative $\mathbf{2 5 f}$ stood out, showing the largest inhibition zone. Moreover, compound 25a presented more pronounced antifungal activity against C. albicans [54].

The pyrazolines are well described in literature as having analgesic [55], anti-inflammatory [56], antibacterial [57], antifungal [57] and antitumoral [58] properties. As another examples of the use of MAOS applied to medicinal chemistry, Manna and co-workers described the synthesis of 1,3,5-tri-substituted indophenazyl-pyrazoline derivatives $\mathbf{3 0 a}-\mathbf{n}$ and their antimicrobial activity against multi-resistant bacteria [59].

The preparation of derivatives 30a-n was conducted in a domestic microwave oven following the synthetic route shown in Figure 9. For this example, reaction time and yields are much better by using microwave irradiation in the place of conventional heating [59].

Figure 9. Synthesis of pyrazoline derivatives 30a-n.

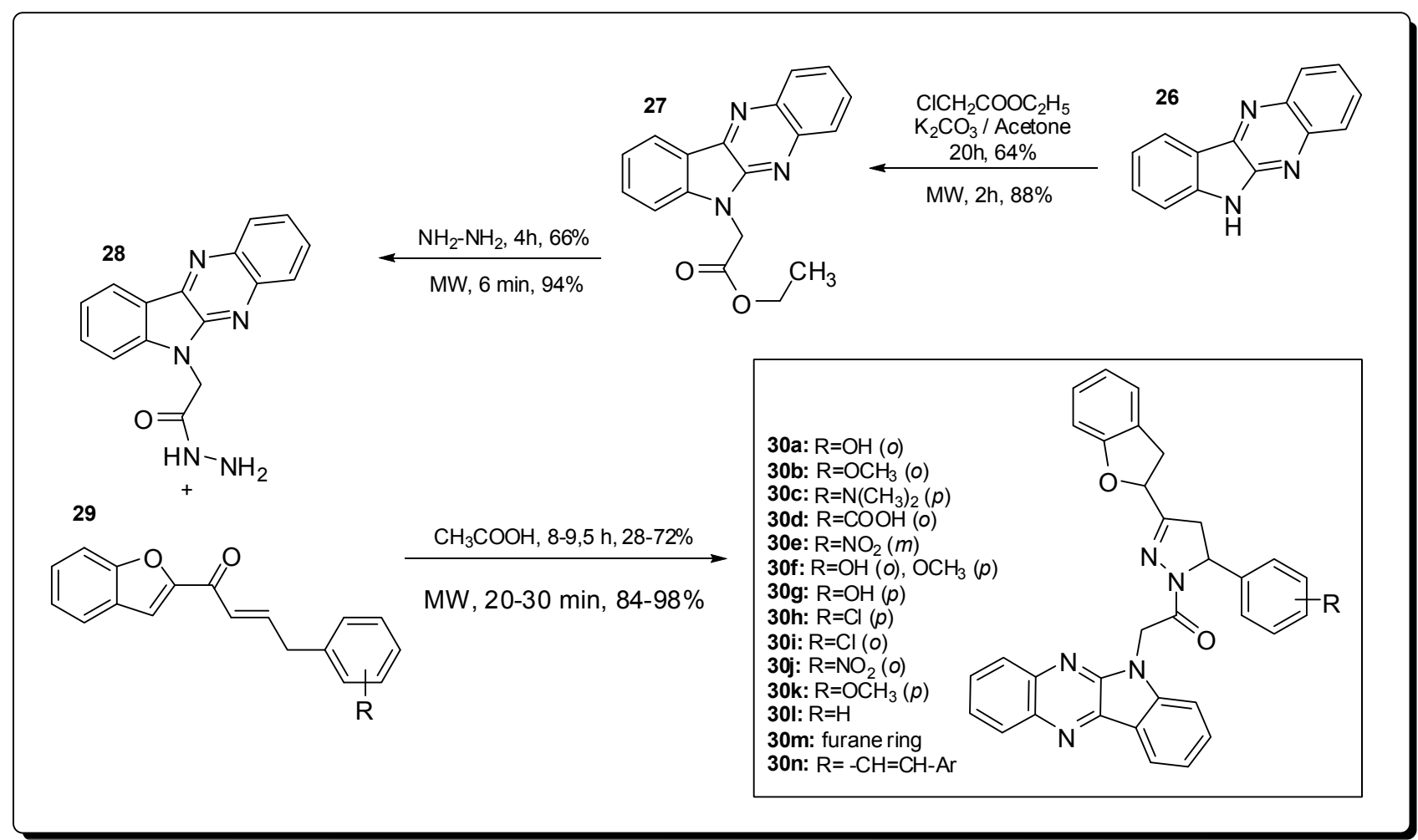

Excepting compounds 30d and 30m, all 1,3,5-trisubstruted indophenazyl-pyrazoline derivatives 30a-n showed good activity against $S$. pyogenes. The minimum inhibitory concentrations (MICs) of derivatives 30a-n are adequate when compared with standard fluoroquinolone drugs. Additionally, the derivatives 30a, 30e, 30j, 30k and 30l have shown the best antimicrobial activities against E. coli, P. aeruginosa, S. typhi and S. aureus [59].

\section{Antivirals}

Among the diseases caused by viruses, hepatitis $\mathrm{C}$ is one of the most serious public health problems, affecting about $3 \%$ of the World's population, which represents about 170 million infected people [60]. The current treatment against hepatitis $\mathrm{C}$ virus (HCV) consists in the use of pegylated 
interferon- $\alpha$ in combination with ribavirin [61]. However, this therapy is only effective in about $50 \%$ of the patients and is associated with serious side effects [61]. Therefore, it is necessary to find out more efficacious and better tolerated antiviral lead compounds. For this purpose, Zhu and colleagues have designed novel acyclic 1,2,4-triazole nucleosides 31 with various ethynyl moieties appended on the triazole nucleobase [62] (Figure 10).

Figure 10. Synthesis of a series of compounds designed against the hepatitis $C$ virus.

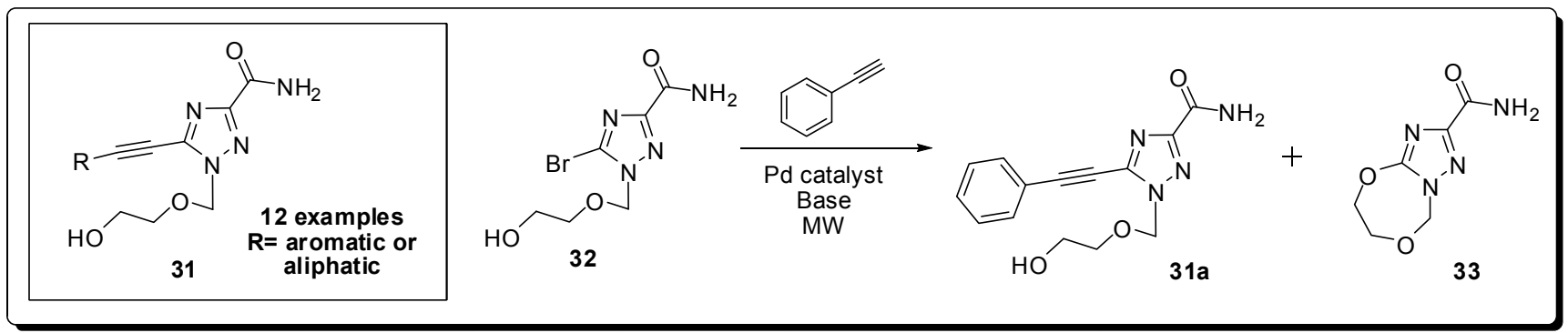

The desired molecules were synthesized efficiently, in yields ranging from 75 to $99 \%$ starting from bromotriazole acyclonucleoside 32 using an efficient one-step Sonogashira reaction in aqueous solution and under microwave irradiation using a scientific microwave reactor. To avoid the formation of the intramolecular cyclization byproduct $\mathbf{3 3}$ under basic conditions, optimized conditions $\left[\mathrm{Pd}\left(\mathrm{PPh}_{3}\right)_{4} / \mathrm{CuI}\right.$ and $\mathrm{Li}_{2} \mathrm{CO}_{3}$, in dioxane/ $\mathrm{H}_{2} \mathrm{O}(3: 1, \mathrm{v} / \mathrm{v})$ as solvents for $25 \mathrm{~min}$ at $100{ }^{\circ} \mathrm{C}$ in a sealed vessel] were developed. One of the compounds ( $\mathrm{R}=$ para-fluorphenyl) inhibited HCV subgenomic replication with a $50 \%$ effective concentration $\left(\mathrm{EC}_{50}\right)$ of $22 \mu \mathrm{g} / \mathrm{mL}$ and did not inhibit proliferation of the host cell at a concentration of $50 \mu \mathrm{g} / \mathrm{mL}$ [63].

Another target identified as a binding partner for the hepatitis $\mathrm{C}$ Virus envelope glycoprotein E2 (HCV-E2) is the large extracellular loop (LEL) of the human CD81 cell surface protein, a member of the tetraspanin family [64]. Since inhibition of this interaction prevents HCV from infecting hepatocytes, the HCV principal target cells [64], Holzer et al. aimed to prepare compounds which restrain the CD81-LEL-HCV-E2 interaction by binding to the LEL [65]. His group started the work by using a biological screening of natural products, current drugs and their in-house substance library (approximately 350 compounds, including several structurally different antihistamines) using a medium throughput assay [66]. Terfenadine (34) was found to be a moderate inhibitor of the CD81-LEL-HCV-E2 interaction $(27 \%$ at $50 \mu \mathrm{M})$.

Figure 11. Synthesis of terfenadine analogues.

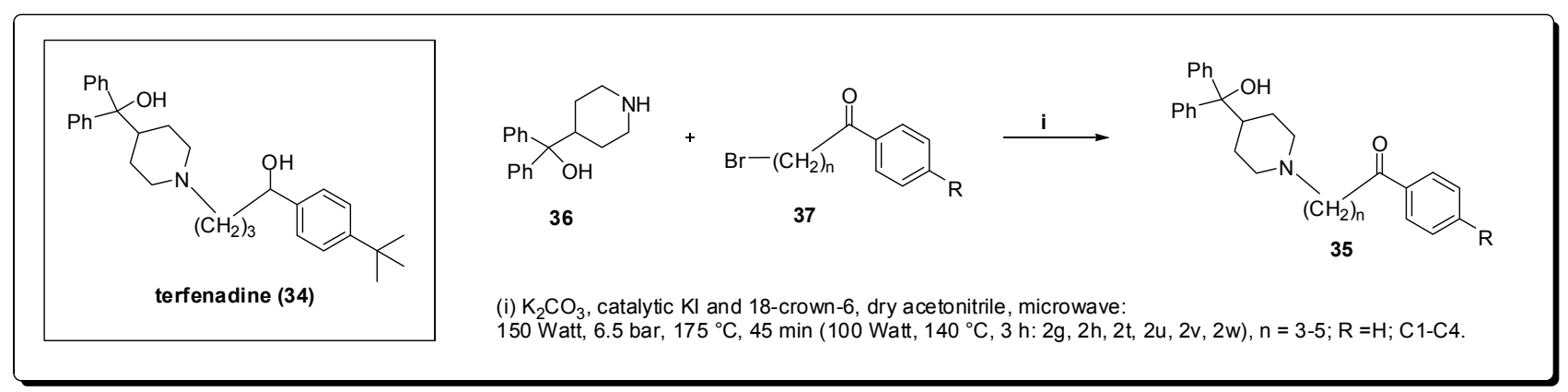


Precursors 37 were coupled to azacyclonol to furnish the planned terfenadine analogues $\mathbf{3 5}$ in good yields and short time (5-45 minutes) using MAOS [67] (Figure 11). The obtained ketoaryl-piperazine derivatives 35 presented an optimization regarding to the CD81-LEL-HCV-E2 interactions that resulted in an inhibitory profile of $69 \%$ at $50 \mu \mathrm{M}$.

Regarding the anti-HIV therapy, the research for novel nucleoside analogues with high potency, low toxicity, and favorable resistance profiles [68] continues to be the cornerstone of this branch of anti-viral drug development [69]. In 1964, the first synthesis of an L-nucleoside was reported [70]; however, only natural D-nucleosides were assumed, during decades, to exhibit biological activity due to the stereospecificity of enzymes in living systems [71,72]. As a consequence, little attention was paid to L-nucleoside analogues until the 1990s with the discovery of lamivudine (38) that exhibited potent antiviral activity against HIV-1 and HBV [73-75] (Figure 12).

Figure 12. Lamivudine chemical structure and the reaction used for the optimization of the transglycosylation reaction with 3-azido nucleosides.

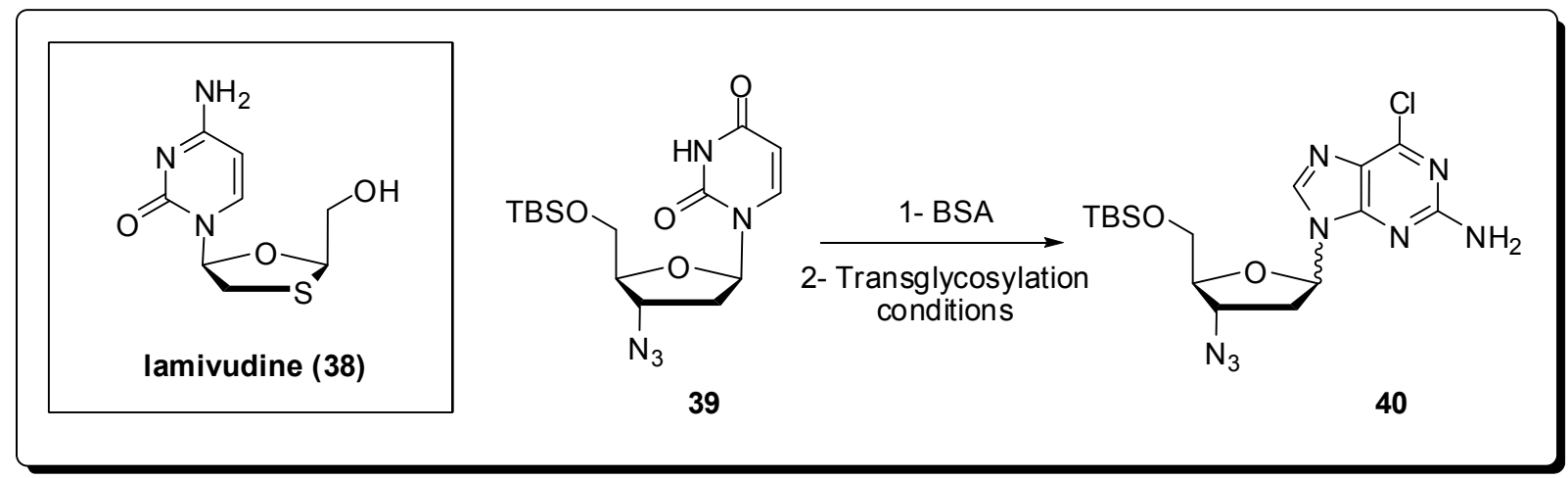

Zang et al. have described a rapid, simple, and general microwave assisted transglycosylation reaction for the synthesis of several azidopurine nucleosides presenting both D- and L-configuration [76]. They examined the effect of different Lewis acids as $\mathrm{SnCl}_{4}$, TMSI, TMSOTf, and Ti(O $i$-Pr $)_{4}$ with potential to affect the transglycosylation of $\mathbf{3 9}$ to $\mathbf{4 0}$. $\mathrm{SnCl}_{4}$ was found to be incompatible with $\mathbf{3 9}$ and led to formation of complex mixtures, whereas the use of $\mathrm{Ti}(\mathrm{O} i-\mathrm{Pr}) 4$ resulted in no reaction. When TMSI was utilized, derivative 40 was obtained in low yields as a 1.2:1 mixture isomers $\alpha$ and $\beta$. TMSOTf provided an 1:1 anomeric mixture of 40, in yields higher than any other Lewis acid tested. Based on the reported microwave-assisted Vorbrüggen glycosylation reaction which was optimized to a $5 \mathrm{~min}$ ribosylation reaction at $130{ }^{\circ} \mathrm{C}$ [77], they began their studies with variation of the reaction temperature using a scientific microwave reactor. The stability of the azido group to TMSOTf at elevated temperature was evaluated and the best yields with minor degradation of $\mathbf{4 0}$ were obtained at $105{ }^{\circ} \mathrm{C}$ and $120^{\circ} \mathrm{C}$ with 10 minutes of heating and 2.7 equiv. of TMSOTf. The synthesized compounds were evaluated for antiviral activity against both HIV and the L-AZA prodrug 41, demonstrating significant anti-HIV activity with an $\mathrm{EC}_{50}$ value of $1.4 \mu \mathrm{M}$ (Figure 13 ). 
Figure 13. Chemical structure of the L-AZA prodrug 41.

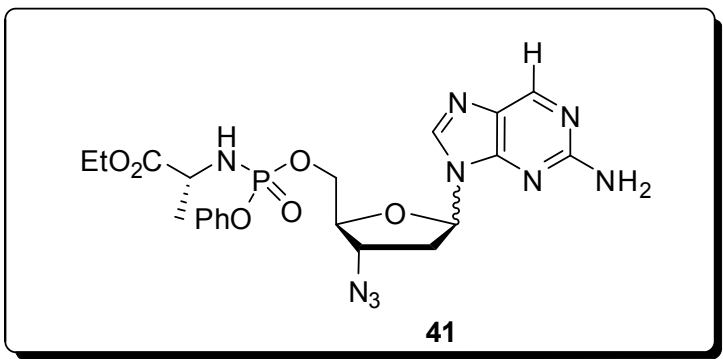

\section{Neglected Diseases}

One of the most neglected diseases in the World is the Human African Trypanosomiasis (HAT or sleeping sickness), which is caused by two subspecies of the parasite T. brucei, namely Trypanosoma brucei rhodesiense (causing East African sleeping sickness) or Trypanosoma brucei gambiense (causing West African sleeping sickness). Annually, approximately 50,000 people are reported with this disease and it is estimated that more than 300,000 are infected, but have not been diagnosed or treated [78-82].

There is an urgent need for more effective treatments for HAT, as the current therapy has many shortcomings, viz. high toxicity, prohibitive costs, undesirable routes of administration as well as poor efficacy. The parallel synthesis of a series of 1,4-benzodiazepin-2,5-diones 43 (Figure 14), structurally related to the paullone nucleus 42, was recently reported [83] as presenting antileishmanial and antitrypanosomal activities [84]. Due to the structural similarity of this series with 1,4-benzodiazepine2-ones (BZDs), the synthesis and biological evaluation of a chemolibrary of the latter and their evaluation as antitrypanosomal agents showing moderate to good trypanocidal activity was described.

Figure 14. (a) Structures of paullone and benzodiazepines; (b) Reduction methodology used to obtain the corresponding amino compounds.

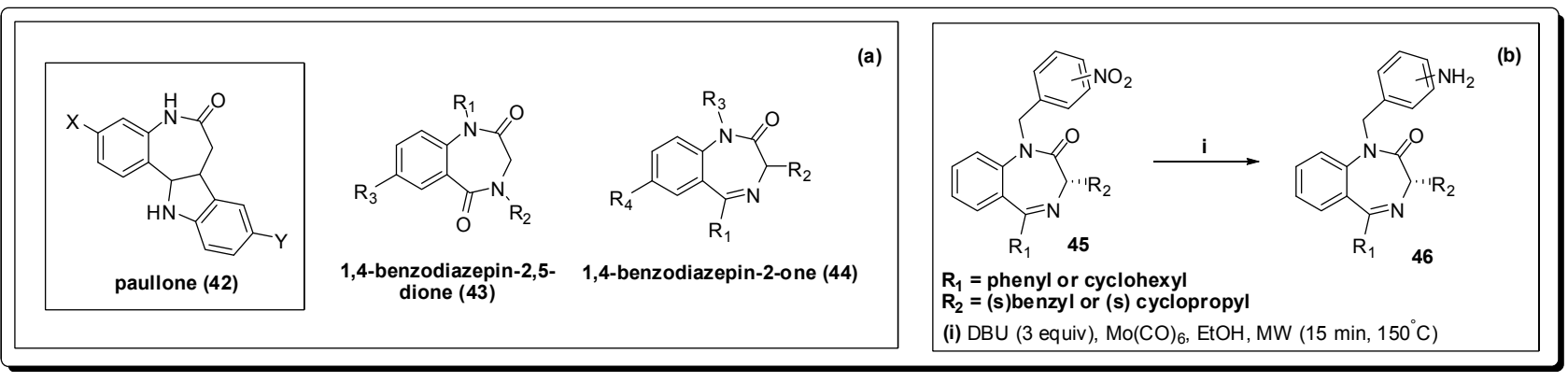

Microwave synthesis was used in order to create the $N$-benzyl series of analogues that presented moderated activity against trypanosomes [85]. The nitro compounds $\mathbf{4 5}$ was exploited as precursor of the corresponding anilines $\mathbf{4 6}$, in yields ranging from 74 to $99 \%$, by using molybdenum hexacarbonyl and DBU at $150^{\circ} \mathrm{C}$ in a sealed tube for $15 \mathrm{~min}$ under microwave irradiation [86,87].

Malaria is a major cause of death, illness and poverty for approximately half of the world's population [88]. It is a parasite-inflicted disease, which is spread throughout the tropical regions of the world by female mosquitoes of the genus Anopheles. Four species of protozoal parasites of the Plasmodium genus cause malaria in humans, i.e., Plasmodium falciparum, Plasmodium malariae, 
Plasmodium ovale and Plasmodium vivax. Despite of considerable scientific advances and the development of new drugs, malaria is reported to cause over one million fatal cases annually, the majority being children under the age of five [88]. The constant emergence of parasitic strains resistant to the currently available antimalarial agents implies an acute need for new therapeutic agents with novel routes of action [89].

Twelve $\alpha$-substituted norstatines 47 were designed (Figure 15), synthesized and evaluated for their inhibitory potencies against plasmepsin II and the plasmepsin IV orthologues (PM4) present in the digestive vacuoles of all four Plasmodium species causing malaria in man. The best compounds provided $K_{i}$ values in the nanomolar range for all PM4, with a best value of $110 n \mathrm{M}$ in PM4 from Plasmodium ovale [90].

Figure 15. Generic structure of the designed $\alpha$-substituted norstatine inhibitors with variable length of the tether to the P1-phenyl group, variations in the P10-group and two tunable stereocenters $(*)$.

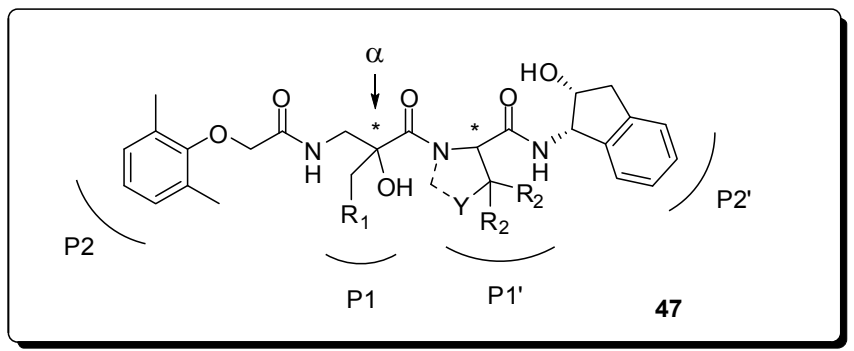

The tertiary alcohol building blocks reported for the construction of $\alpha$-benzylnorstatines and $\alpha$-phenylnorstatines are prepared from the respective epoxy acids $\mathbf{4 8 a}$ or $\mathbf{4 8 b}$. The novel, four-step synthetic route to these key intermediates is outlined in Figure 16. The acrylic acid 49a was prepared by a Knoevenagel reaction, by applying a similar procedure to that previously reported for the synthesis of $49 \mathbf{b}$ [91]. Attempts to perform the direct epoxidation of $49 \mathbf{a}, \mathbf{b}$ were not successful. Thus, a fast and convenient one-pot microwave irradiation (MW) protocol for esterification was developed, in order to generate the corresponding ethyl ester $\mathbf{5 0 a}, \mathbf{b}$. The esters were then readily oxidized by 3-chloroperbenzoic acid (mCPBA) to provide the epoxides 51a,b. The building blocks, 48a,b, were obtained by hydrolysis of the ester.

Figure 16. Synthesis of the P1 moieties.

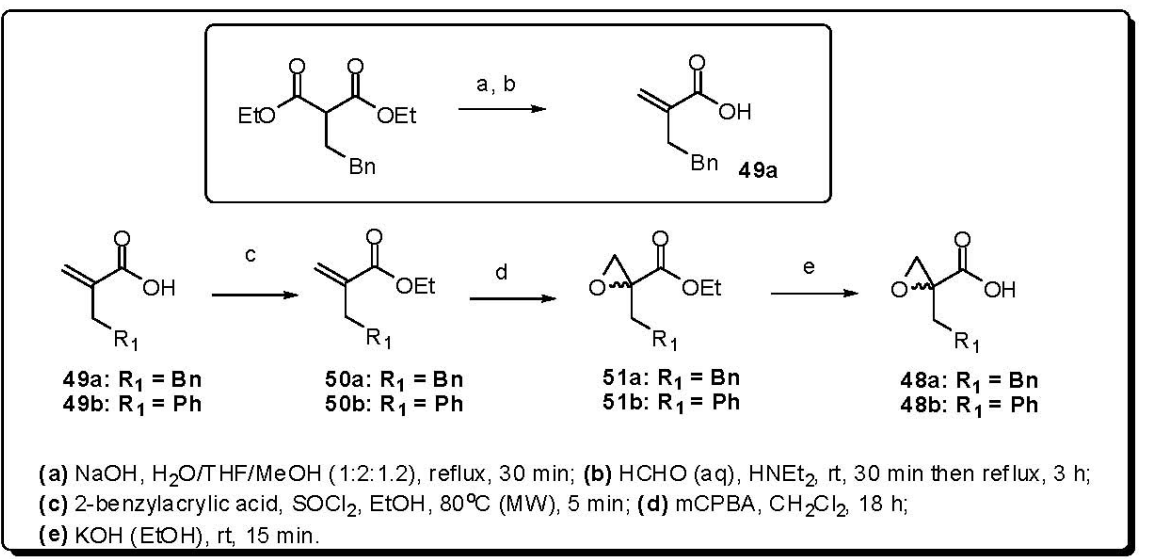


Leishmaniasis is caused by protozoan parasites belonging to the genus Leishmania and is one of the most widespread parasitic diseases been endemic in 89 countries and its visceral form, caused by Leishmania donovani, leads to 5,000,000 new cases and 50,000 deaths per year [92]. Commonly a well-known antiprotozoan aromatic diamidine, pentamidine (52, Figure 17) [93], is used against various infectious diseases such as leishmaniasis [94,95], HIV-related Pneumocystis jirovecii opportunistic pneumonia [96] and trypanosomiasis [94,97]. Despite of its wide antimicrobial spectrum, its use remains limited due to its high toxicity, in particular nephro-, cardio- and neurological toxicities $[93,98]$.

Figure 17. Compounds with antileishmanial activity.

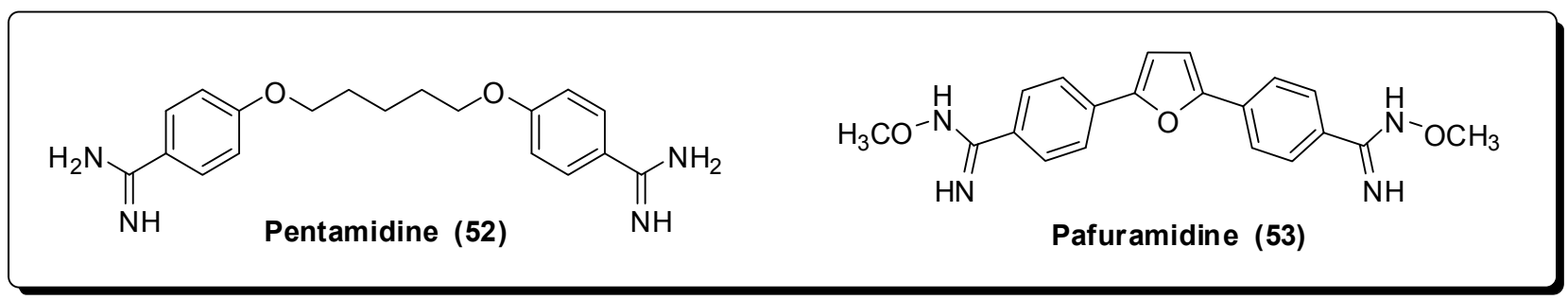

Arylamidines are known to bind to the minor groove of AT DNA sequences along the phosphodiester backbone [99,100]. Two amidinium end groups appear to be necessary for this interaction [101] while the central part of the drug inserts into the minor groove. However, the amidine group presents poor oral bioavailability due to its protonation in the biophase needing parenteral administration. Pafuramidine (53, Figure 17) has shown interesting activities against $L$. donovani and presented good oral bioavailability owing to the replacement of amidines by methoxyamidoximes $\mathbf{5 2}$ [102].

A new series of monoamidoxime derivatives $\mathbf{5 4}$ was designed by Paloque and colleagues and synthesized using manganese(III) acetate by means of microwave irradiation using a multimode microwave oven, specifically in the synthesis of the 2,3-dihydrofuran intermediates 55 from several $\beta$-ketosulfones 56 (Figure 18) [103]. Some amidoximes showed interesting in vitro activities toward Leishmania donovani promastigotes with $\mathrm{IC}_{50}$ values between 5.21 and $7.89 \mu \mathrm{M}$. Additionally, the cytotoxicity of the synthesized compounds was evaluated revealing the corresponding selectivity index (SI), where four amidoxime derivatives $\mathbf{5 4}$ have exhibited an SI more than 20 times better than pentamidine (52).

Figure 18. New series of monoamidoxime derivatives.

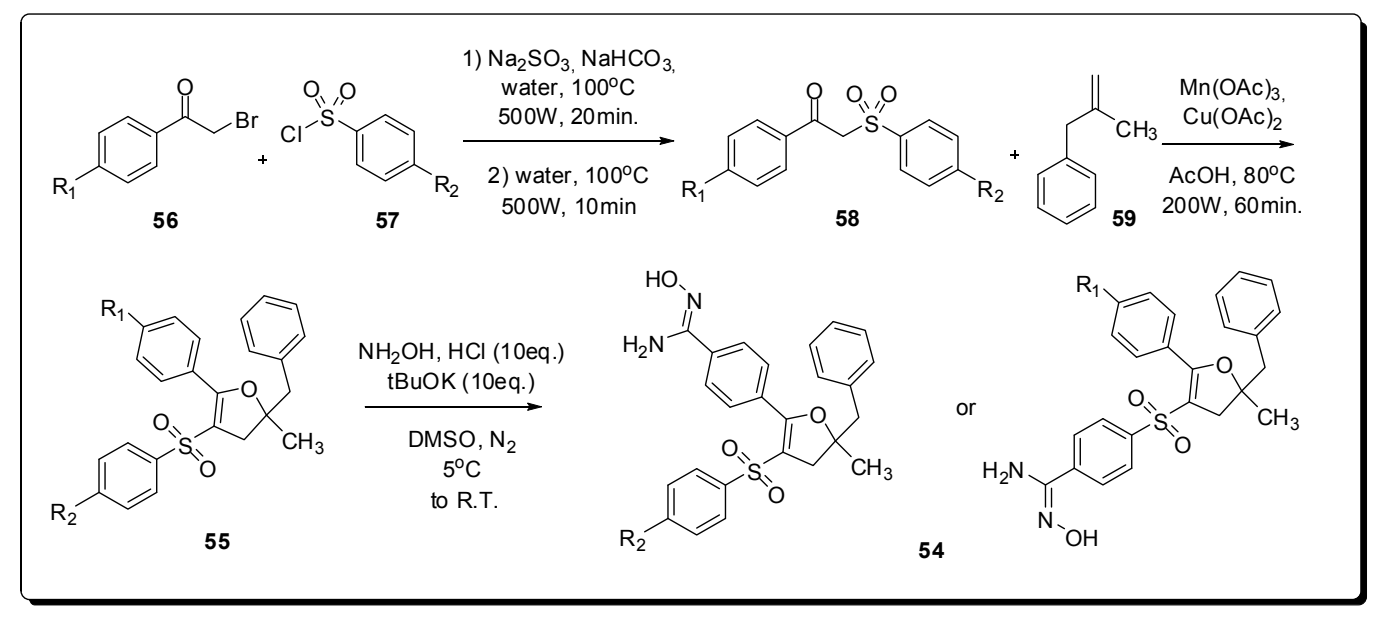




\section{Central Nervous System}

The central nervous system (CNS) drug market accounted for 15\% (around U\$ 118 billion) of the pharmaceutical market sales in 2008 [104]. In contrast with the neglected diseases, the major part of CNS diseases affects people of all countries and economical classes. In this context, there are many efforts to develop novel drug candidates, for example: with hypnotic and sedative effects [105], as alternative for the treatment of neuropathic pain [106] and other analgesic effects [107].

Among the compounds of $\mathrm{N}$-acylhydrazones class developed in our research group, the major part of them presents both, analgesic and anti-inflammatory profiles [53]. Recently, we have discovered two compounds (60 and 61, Figure 19), that have inhibited the abdominal constrictions induced by $\mathrm{AcOH}$ in mice in $50 \%$ and $\mathrm{ED}_{50}$ of approximately $2 \mathrm{mg} / \mathrm{Kg}$, for both compounds [107].

Figure 19. $N$-acylhydrazones with analgesic activity.

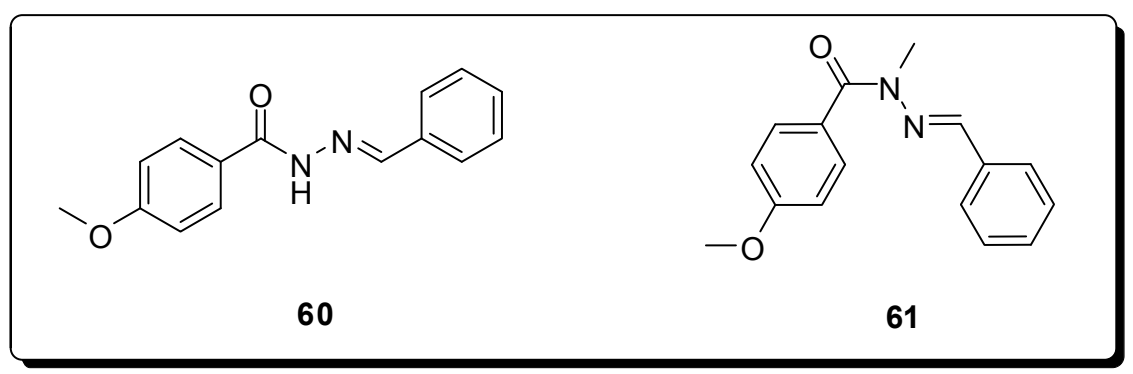

Based on this results, were proposed conformational restrictions of $\mathbf{6 0}$ and $\mathbf{6 1}$, as a strategy to elucidate the bioactive conformations, constructing heterocyclic rings mimetic to $\mathrm{N}$-acylhydrazone framework. A scientific microwave reactor was used to construct three heterocyclic conformationally-restricted derivatives [107]. For the construction of quinazoline scaffold of 64 (Figure 20), MAOS allowed the synthesis of the quinazolinone intermediate $\mathbf{6 3}$ from the reaction between anthranilic acid $\mathbf{6 2}$ and formamidine acetate in good yield (87\%). In this case, conventional heating resulted in the formation of 63 in lower yields.

Figure 20. Use of MAOS to construct quinazoline scaffold.
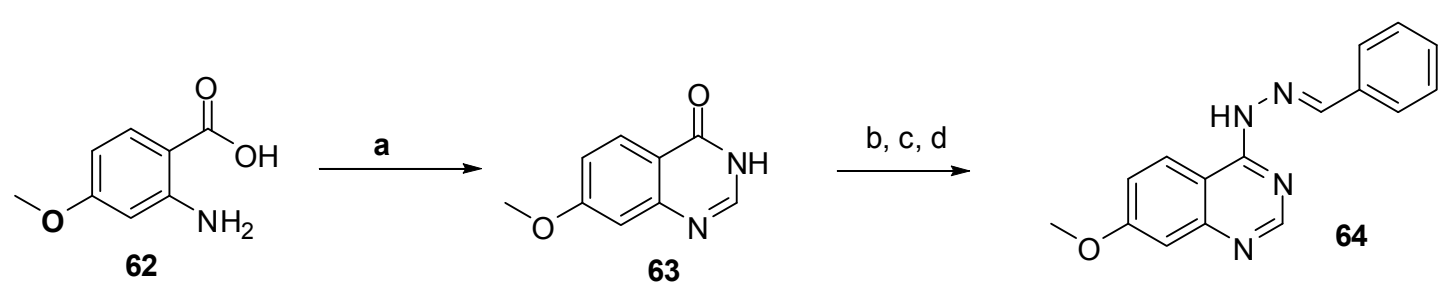

(a) formamidine acetate, EtOH, $\mathrm{MW} 120^{\circ} \mathrm{C}, 40 \mathrm{~min}, 87 \%$; (b) $\mathrm{POCl}_{3}, 90^{\circ} \mathrm{C}, 1 \mathrm{~h}, 97 \%$; (c) hydrazine monohydrate, $90^{\circ} \mathrm{C}, 6 \mathrm{~h}, 88 \%$; (d) benzaldehyde, EtOH, HClcat, $1 \mathrm{~h}, 92 \%$.

The second conformationally-restricted heterocyclic compound 67 was constructed through the Suzuki cross coupling between the phenyl boronic acid and the tosyl phthalazone 66, resulting in the formation of 67 in only 20 minutes and good yield (77\%) (Figure 21) [107]. 
Figure 21. Use of MAOS to construct phthalazinone scaffold.

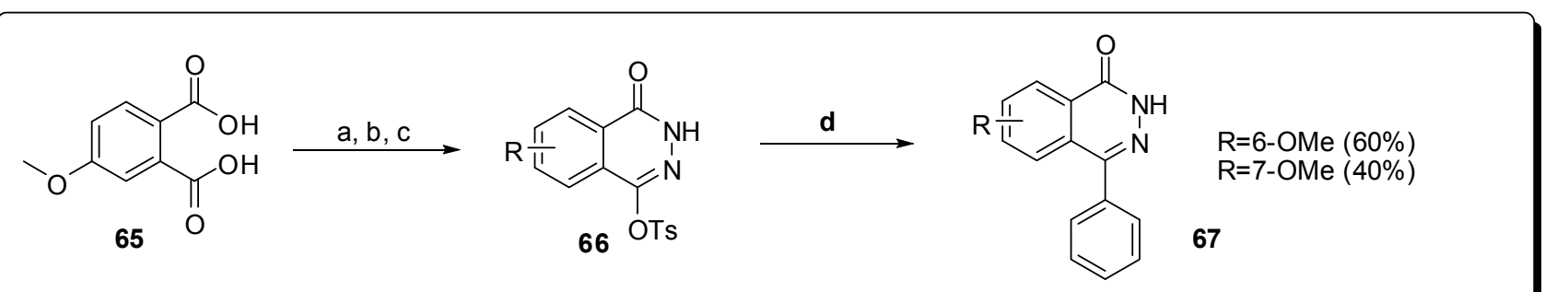

(a) acetic anhydride, $120^{\circ} \mathrm{C}, 1 \mathrm{~h}$; (b) $\mathrm{NH}_{2} \mathrm{NH}_{2} \cdot \mathrm{H}_{2} \mathrm{SO}_{4}, \mathrm{DME}: \mathrm{H}_{2} \mathrm{O}, 90^{\circ} \mathrm{C}, 20 \mathrm{~h}, 82 \%$, in two steps; (c) tosyl chloride, pyridine, $80^{\circ} \mathrm{C}, 6 \mathrm{~h}, 74 \%$; (d) phenylb oronic acid, $\mathrm{Pd}\left(\mathrm{Ph}_{3}\right)_{4}, \mathrm{Na}_{2} \mathrm{CO}_{3}, \mathrm{DME}: \mathrm{H}_{2} \mathrm{O}, \mathrm{MW} 155^{\circ} \mathrm{C}, 20 \mathrm{~min}, 77 \%$.

The third conformationally-restricted heterocyclic compound, a benzodiazepinone (70), were obtained through a Pd-catalyzed cross coupling, but in this case, the Sonogashira cross coupling was used to obtain the acetylenic derivative 69 (Figure 22). The use of MAOS was important for the reduction of the reaction time required the obtain $\mathbf{6 9}$, i.e., 20 minutes at $120^{\circ} \mathrm{C}$ (Figure 22), which was next cyclized to form $\mathbf{7 0}$ [107].

Figure 22. Use of MAOS to construct benzodiazepinone scaffold.

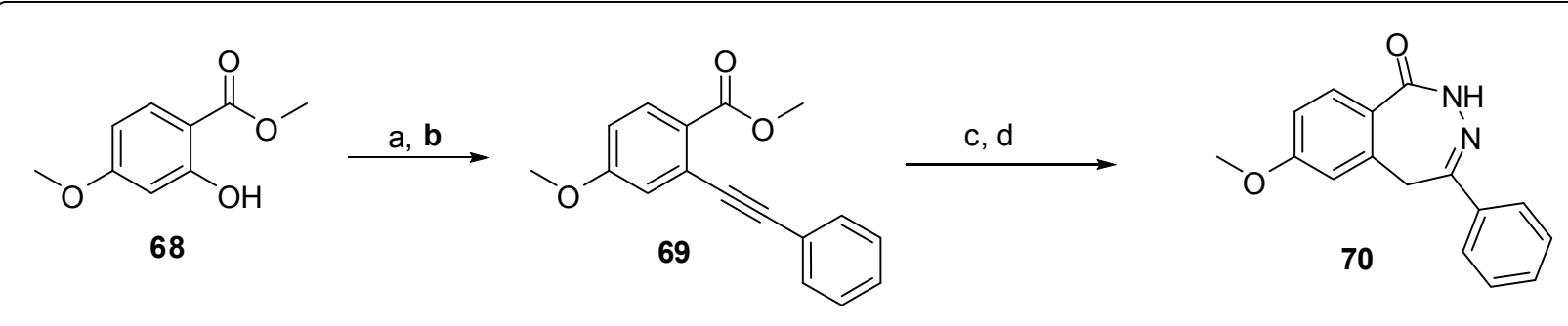

(a) tríflic anhydride, $\mathrm{CH}_{2} \mathrm{Cl}_{2}, \mathrm{Et}_{3} \mathrm{~N}, 0^{\circ} \mathrm{C}, 1 \mathrm{~h}, 93 \%$; (b) phenylacetylene, $\mathbf{C H}_{3} \mathbf{C N}, \mathrm{Et}_{3} \mathbf{N}, \mathbf{P d C l}_{2}\left(\mathbf{P P h}_{3}\right)_{2}, \mathbf{P P h}, \mathbf{M W}$ $120^{\circ} \mathrm{C}, 20 \mathrm{~min}, 89 \%$; (c) TFA, $6 \mathrm{~h}, 89 \%$. (d) $\mathrm{NH}_{2} \mathrm{NH}_{2} \cdot \mathrm{H}_{2} \mathrm{O}, \mathrm{n}-\mathrm{BuOH}, 90^{\circ} \mathrm{C}, 6 \mathrm{~h}, 79 \%$.

The antinociceptive effect of $\mathrm{N}$-acylhydrazone derivatives $\mathbf{6 0}$ and $\mathbf{6 1}$ in $\mathrm{AcOH}$-induced abdominal constrictions in mice induced by acetic acid was better than the effect observed for 64, 67 and 70. However the three conformationally-restricted derivatives presented analgesic potencies equivalent to paracetamol used as standard drug [107].

Another good example of MAOS applied to medicinal chemistry from our laboratory is related with the synthesis of four heterotricyclic neuroactive compounds $\mathbf{7 5 a - d}$. They were evaluated in hypnotic, locomotor and analgesic activity protocols [108,109]. In the pentobarbital-induced-sleep test [110], the nitro-derivative 75d has shown an important hypnotic behavior with duration of approximately 160 minutes at $6 \mathrm{mg} / \mathrm{Kg}$ dose. On the locomotor activity test in mice [111], the compounds $75 \mathrm{a}(6 \mathrm{mg} / \mathrm{Kg}, 93.7 \pm 15.2 \mathrm{mov} / \mathrm{min})$ and $75 \mathrm{~d}(4 \mathrm{mg} / \mathrm{Kg}, 86.7 \pm 16.5 \mathrm{mov} / \mathrm{min})$ stand out as being more active to promote a sedative effect, statistically equivalent to the reference drug midazolam $[108,109,112]$ in a dose of $2 \mathrm{mg} / \mathrm{Kg}$. The analgesic activity was evaluated in the hot plate test in mice [113] and the pyrazolo[3,4-b]pyrrolo[3,4- $d]$ pyridine derivative $75 \mathbf{d}$ presented the best analgesic activity $(100 \%$ in the dose of $2 \mathrm{mg} / \mathrm{Kg})$ after only 30 minutes. 
Before the construction of the four heterotricyclic compounds $\mathbf{7 5 a}-\mathbf{d}$, the azadiene $\mathbf{7 2}$ was prepared in excellent yield (98\%), through the reaction between the phenylpyrazolamine $\mathbf{7 1}$ and the $\mathrm{N}, \mathrm{N}$-dimethylformamide dimethylacetal. In addition, the phenylmaleimides $\mathbf{7 4 a}-\mathbf{d}$ were constructed by the condensation of para-substituted anilines 73a-d with maleic anhydride in yields ranging from $72 \%$ to $83 \%[108,109,114]$. The pyrazolo[3,4- $b]$ pyrrolo[3,4- $d]$ pyridine derivatives $\mathbf{7 5 a}-\mathbf{d}$ were constructed in a key cycloaddition step between the azadiene $\mathbf{7 2}$ and functionalized phenylmaleimides $\mathbf{7 4 a - d}$, in very low (20-35\%) yields and very long reaction times (48 hours) when conventional heating was used (Figure 23) [108,109,114].

Figure 23. Synthesis of the intermediates $\mathbf{7 2}$ and $\mathbf{7 4 a - d}$ followed by the hetero Diels-Alder step exploited to obtain the pyrazolo[3,4-b]pyrrolo[3,4- $d]$ pyridine derivatives 75a-d.

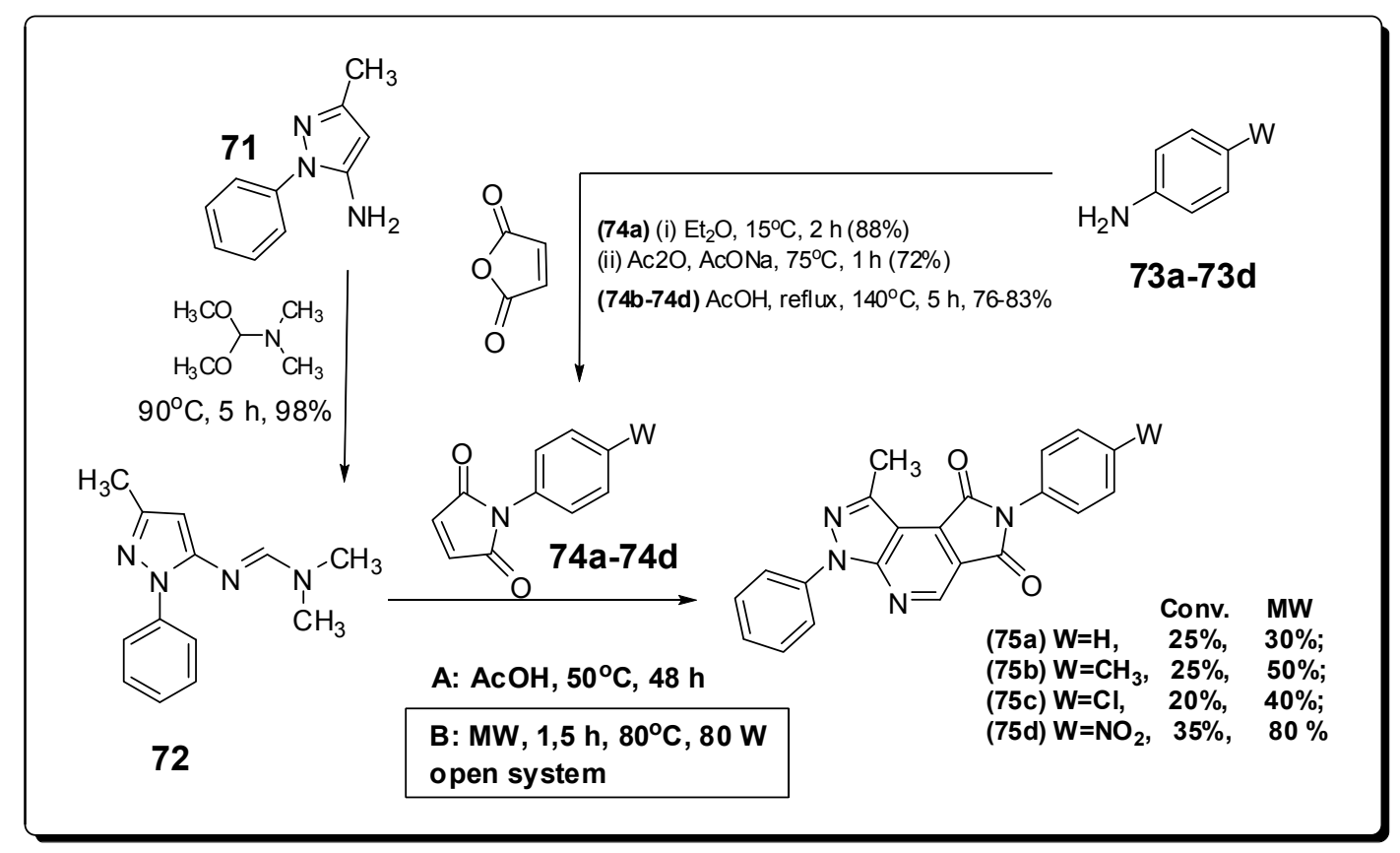

Based on the literature of MAOS applied to the synthesis of other heterocyclic compounds obtained by cycloaddition strategy [115-117], we have developed a new methodology to construct the pyrazolo[3,4-b]pyrrolo[3,4- $d]$ pyridine derivatives $\mathbf{7 5 a - d}$ in a scientific microwave reactor using a new free-solvent methodology. For the four heterotricyclic derivatives 75a-d the reaction time was reduced from 48 hours to 1.5 hours and in the case of the heterocyclic compound $\mathbf{7 5 d}$, the yield was increased from 35 to $80 \%$ [114].

\section{Conclusions}

The extensive use of microwave irradiation for the synthesis of molecules of pharmacological interest has contributed to improve the access to different chemical scaffolds by applying new methodologies and techniques. For this reason, the initial limitations faced in MAOS seem to be disappearing and these facts encourage its use as the first option for the synthesis of new drug candidates, specially based on the benefits related to better yields and shorter reaction times. As could be exemplified in this review, there are research groups using MAOS to find out hits and lead-compounds related with different biological targets and diseases in the last years. In spite of the 
scale up limitations in MAOS, continuous flow technique and large reactors use have achieved good results in the challenge to obtain the amounts of substance required by the pharmaceutical industry for pre-clinical and clinical phases of the drug development process.

\section{Acknowledgments}

The authors thank CAPES (BR), CNPq (BR), FAPERJ (BR) and INCT-INOFAR (BR, \#573.564/2008-6) for financial support and fellowships.

\section{References}

1. Gedye, R.; Smith, F.; Westaway, K.; Ali, H.; Baldisera, L.; Laberge, L.; Rousell, J. The use of microwave ovens for rapid organic synthesis. Tetrahedron Lett. 1986, 27, 279-282.

2. Giguere, R.J.; Bray, T.L.; Duncan, S.M.; Majetich, G. Application of commercial microwave ovens to organic synthesis. Tetrahedron Lett. 1986, 27, 4945-4948.

3. Lidström, P.; Tierney, J.; Wathey, B.; Westman, J. Microwave assisted organic synthesis - a review. Tetrahedron 2001, 57, 9225-9283.

4. Bougrin, K.; Loupy, A.; Soufiaoui, M. Microwave-assisted solvent-free heterocyclic synthesis. J. Photochem. Photobiol. C Photochem. Rev. 2005, 6, 139-167.

5. Pérez-Picaso, L.; Escalante, J.; Olivo, H.F.; Rios, M.Y. Efficient microwave assisted syntheses of 2,5-Diketopiperazines in aqueous media. Molecules 2009, 14, 2836-2849.

6. Hügel, H.M. Microwave multicomponent synthesis. Molecules 2009, 14, 4936-4972.

7. Kappe, C.O. High-speed combinatorial synthesis utilizing microwave irradiation. Curr. Opin. Chem. Biol. 2002, 6, 314-320.

8. Kong, L.; Lv, X.; Lin, K.; Liu, X.; Zhou, Y.; Jia, Y. Efficient synthesis of imidazoles from aldehydes ans 1,2-Diketones under superheating continuous by using a continuous flow microreactor system under pressure. Org. Proc. Res. Dev. 2010, 14, 902-904.

9. Schmink, J.R.; Kormos, C.M.; Devine, W.G.; Leadbeater, N.E. Exploring the scope for scale up of organic chemistry using a large batch microwave reactor. Org. Proc. Res. Dev. 2010, 14, 205-214.

10. Patil, S.A.; Patil, R.; Miller, D.D. Microwave-assisted synthesis of medicinally relevant indoles. Curr. Med. Chem. 2011, 18, 615-637.

11. Zhao, Z.; Wisnoski, D.D.; Wolkenberg, S.E.; Leister, W.H.; Wang, Y.; Lindsley, C.W. General microwave-assisted protocols for the expedient synthesis of quinoxalines and heterocyclic pyrazines. Tetrahedron Lett. 2004, 45, 4873-4876.

12. Chilin, A.; Marzaro, G.; Zanatta, S.; Guiotto, A. A microwave improvement in the synthesis of the quinazoline scaffold. Tetrahedron Lett. 2007, 48, 3229-3231.

13. Reichelt, A.; Filsey, J.R.; Rzasa, R.M.; Thiel, O.R.; Achmatowicz, M.M.; Larsen, R.D.; Zhang, D. Palladium-catalyzed chemoselective monoarylation of hydrazides for the synthesis of [1,2,4]triazolo[4,3-a]pyridines. Org. Lett. 2009, 12, 792-795.

14. Lucas, R.; Vergnaud, J.; Teste, K.; Zerrouk, R.; Sol, V.; Krausz, P. A facile and rapid iodine-catalyzed meso-tetraphenylporphyrin synthesis using microwave activation. Tetrahedron Lett. 2008, 49, 5537-5539. 
15. Yeung, K.-S.; Farkas, M.E.; Kadow, J.F.; Meanwell, N.A. A base-catalyzed, direct synthesis of 3,5-disubstituted 1,2,4-triazoles from nitriles and hidrazides. Tetrahedron Lett. 2005, 46, 3429-3432.

16. Adib, M.; Jahromi, A.H.; Tavoosi, N.; Mahdavi, H.; Bijanzadeh, H.R. Microwave-assisted one efficient, one pot, three-multicomponent synthesis of 3,5-disubstituted 1,2,4-oxadiazoles under free-solvent conditions. Tetrahedron Lett. 2006, 47, 2965-2967.

17. Andrade, M.M.; Barros, M.T. Fast synthesis of $N$-Acylhydrazones employing a microwave assisted neat protocol. J. Comb. Chem. 2010, 12, 245-247.

18. Baxendale, I.R.; Ley, S.V. Polymer-supported reagents for multi-step organic synthesis: Application to the synthesis of sidenafil. Bioorg. Med. Chem. Lett. 2000, 10, 1983-1986.

19. SCOPUS. Available online: http://www.scopus.com (accessed on 13 September 2011).

20. Kappe, C.O.; Dallinger, D. The impact of microwave synthesis on drug discovery. Nat. Rev. Drug Discov. 2006, 5, 51-64.

21. Larhed, M.; Hallberg, A. Microwave-assisted high-speed chemistry: A new technique in drug discovery. Drug Discov. Today 2001, 6, 406-416.

22. Shipe, W.D.; Wolkenberg, S.E.; Lindsley, C.W. Accelerating lead development by microwaveenhanced medicinal chemistry. Drug Discov. Today Technol. 2005, 2, 155-161.

23. World Health Organization. Available online: http://www.who.int/cancer/en/ (accessed on 1 February 2011).

24. Noble, M.E.M.; Endicott, J.A.; Johnson, L.N. Protein kinase inhibitors: Insights into drug design from structure. Science 2004, 303, 1800-1805.

25. Li, Q.; Zhu, G.D. Targeting serine/threonine protein kinase B/Akt and cell-cycle checkpoint kinases for treating cancer. Curr. Top. Med. Chem. 2002, 2, 939-971.

26. Lindsley, C.W.; Zhao, Z.; Leister, W.H.; Robinson, R.G.; Barnett, S.F.; Defeo-Jones, D.; Jones, R.E.; Hartman, G.D.; Huff, J.R.; Huber, H.E.; et al. Allosteric Akt (PKB) inhibitors: Discovery and SAR of isozyme selective inhibitors. Bioorg. Med. Chem. Lett. 2005, 15, 761-764.

27. Cheng, J.Q.; Lindsley, C.W.; Cheng, G.Z.; Yang, H.; Nicosia, S.V. The Akt/PKB pathway: Molecular target for cancer drug discovery. Oncogene 2005, 24, 7482-7492.

28. Barnett, S.F.; Bilodeau, M.T.; Lindsley, C.W. The Akt/PKB family of protein kinases: A review of small molecule inhibitors and progress towards target validation. Curr. Top. Med. Chem. 2005, 5, 109-125.

29. Caldwell, J.J.; Davies, T.G.; Donald, A.; McHardy, T.; Rowlands, M.G.; Aherne, G.W.; Hunter, L.K.; Taylor, K.; Ruddle, R.; Raynaud, F.I.; et al. Identification of 4-(4-aminopiperidin1-yl)-7H-pyrrolo[2,3-d]pyrimidines as selective inhibitors of protein kinase B through fragment elaboration. J. Med. Chem. 2008, 51, 2147-2157.

30. Caldwell, J.J.; Cheung, K.-M.; Collins, I. Synthesis of 4-(cyclic dialkylamino)-7-azaindoles by microwave heating of 4-halo-7-azaindoles and cyclic secondary amines. Tetrahedron Lett. 2007, 48, 1527-1529.

31. Hajdúch, M.; Havlíèek, L.; Veselỳ, J.; Novotnỳ, R.; Mihàl, V.; Strnad, M. Synthetic cyclin-dependent kinase inhibitors: New generation of potent anti-cancer drugs. Adv. Exp. Med. Biol. 1999, 457, 341-353.

32. Sherr, C.J. Cancer cell cycles. Science 1996, 274, 1672-1677. 
33. López-Cara, L.C.; Conejo-García, A.; Marchal, J.A.; MacChione, G.; Cruz-López, O.; Boulaiz, H.; García, M.A.; Rodríguez-Serrano, F.; Ramírez, A.; Cativiela, C.; et al. New (RS)-benzoxazepinpurines with antitumour activity: The chiral switch from (RS)-2,6-dichloro-9-[1-(pnitrobenzenesulfonyl)-1,2,3,5-tetrahydro-4,1-benzoxazepin-3-yl]-9H-purine. Eur. J. Med. Chem. 2011, 46, 249-258.

34. Díaz-Gavilán, M.; Rodríguez-Serrano, F.; Gómez-Vidal, J.A.; Marchal, J.A.; Aránega, A.; Gallo, M.A.; Espinosa, A.; Campos, J.M. Synthesis of tetrahydrobenzoxazepine acetals with electron-withdrawing groups on the nitrogen atom. Novel scaffolds endowed with anticancer activity against breast cancer cells. Tetrahedron 2004, 60, 11547-11557.

35. Rang, H.P.; Dale, M.M.; Ritter, J.M.; Flower, R.J. (Trad. Do Nascimento, A.P.). Farmacologia $6^{\mathrm{a}}$ ed.; Elsevier: Rio de Janeiro, Brazil, 2007.

36. Dinarello, C.A. Proinflammatory cytokines. Chest 2000, 118, 503.

37. Tillie-Leblond, I.; Pugin, J.; Marquette, C.-H.; Lamblin, C.; Saulnier, F.; Brichet, A.; Wallaert, B.; Tonnel, A.-B.; Gosset, P. Balance between proinflammatory cytokinesand their inhibitors in bronchial lavage from patients with status asthmaticus. Am. J. Respir. Crit. Care Med. 1999, 159, 487-494.

38. Checker, R.; Sharma, D.; Sandur, S.K.; Khanam, S.; Poduval, T.B. Anti-inflammatory effects of plungabin are mediated by inhibition of NF-kappaB activation in lymphocytes. Int. Immunopharmacol. 2009, 9, 949-958.

39. Ferreira, M.A.D.; Nunes, O.D.R.H.; Fontenele, J.B.; Pessoa, O.D.L.; Lemos, T.L.G.; Viana, G.S.B. Analgesic and anti-inflammatory activities of a fraction rich in oncocalyxone A isolated from Auxemma oncocalyx. Phytomedicine 2004, 11, 315-322.

40. Phutdhawong, W.S.; Ruensamran, W.; Phutdhawong, W.; Taechowisan, T. Synthesis of 1,6,7,8-tetrahydro-naphtho[2,3-d]-azepino[4,5b]indole-9,14-diones and their inhibitory effects on pro-inflammatory cytokines. Bioorg. Med. Chem. Lett. 2009, 19, 5753.

41. Phutdhawong, W.; Buddhasukh, D. Facile microwave-assisted synthesis of 9,10-Dihydro-9,10ethanoanthracene-11-carboxylic acid methyl ester. Molecules 2005, 10, 1409-1412.

42. Clark-Lewis, I.; Mattioli, I.; Gong, J.H.; Loetscher, P. Structure-function relationship between the human chemokine receptor CXCR3 and its ligands. J. Biol. Chem. 2003, 278, 289-295.

43. Qin, S.; Rottman, J.B.; Myers, P.; Kassam, N.; Weinblatt, M.; Loetscher, M.; Koch, A.E.; Moser, B.; Mackay, C.R. The chemokine receptors CXCR3 and CCR5 mark subsets of T cells associated with certain inflammatory reactions. J. Clin. Invest. 1998, 101, 746-754.

44. Lazzeri, E.; Romagnani, P. CXCR3-bindind chemokines: Novel multifunctional therapeutic targets. Curr. Drug Targets Immune Endocr. Metabol. Disord. 2005, 5, 109-118.

45. Salomon, I.; Netzer, N.; Wildbaum, G.; Schif-Zuck, S.; Maor, G.; Karin, N. Targeting the function of IFN- $\gamma$-Inducible protein 10 suppresses ongoing adjuvant arthritis. J. Immunol. 2002, $169,2685-2693$.

46. Hancock, W.W.; Lu, B.; Gao, W.; Csizmadia, V.; Faia, K.; King, J.A.; Smiley, S.T.; Ling, M.; Gerard, N.P.; Gerard, C. Requirement of the chemokine receptor CXCR3 for acute allograft rejection. J. Exp. Med. 2000, 192, 1515-1520.

47. Donnelly, L.E.; Barnes, P.J. Chemokine receptors as therapeutic targets in chronic obstructive pulmonary disease. Trends Pharmacol. Sci. 2006, 27, 546-553. 
48. Knight, R.L.; Allen, D.R.; Birch, H.L.; Chapman, G.A.; Galvin, F.C.; Jopling, L.A.; Lock, C.J.; Meissner, J.W.G.; Owen, D.A.; Raphy, G.; et al. Development of CXCR3 antagonists. Part 4: Discovery of 2-amino-(4-tropinyl)quinolines. Bioorg. Med. Chem. Lett. 2008, 18, 629-633.

49. Maes, B.U.W.; Loones, K.T.J.; Lemière, G.L.F.; Dommisse, R.A. Rapid palladium-catalyzed aminations of aryl chlorides with aliphatic amines under temperature-controlled microwave heating. Synlett 2003, 12, 1822-1825.

50. Hardman, J.; Limbird, L.E. Goodman \& Gilman's the Pharmacological Basis of Therapeutcs, 10th ed.; McGraw-Hill: New York, NY, USA, 2001.

51. Schmid, M.B. Novel approaches to the discovery of antimicrobial agents. Curr. Opin. Chem. Biol. 1998, 2, 529-534.

52. Rollas, S.; Küçükgüzel, S.G. Biological activities of hydrazone derivatives. Molecules 2007, 12, 1910-1939.

53. Fraga, C.A.M.; Barreiro, E.J. Medicinal chemistry of N-Acylhydrazones: New lead-compounds of analgesic, antiinflammatory and antithrombotic drugs. Curr. Med. Chem. 2006, 13, 167-198.

54. Ajani, O.O.; Obafemi, C.A.; Nwinyi, O.C.; Akinpelu, D.A. Microwave assisted synthesis and antimicrobial activity of 2-quinoxalinone-3-hydrazone derivatives. Bioorg. Med. Chem. 2010, 18, 214-221.

55. Amir, M.; Kumar, H.; Khan, S.A. Synthesis and pharmacological evaluation of pyrazoline derivatives as new anti-inflammatory and analgesic agents. Bioorg. Med. Chem. Lett. 2008, 18, 918-922.

56. Chakrabarthi, K.J.E.; Richard, J.G.; Peter, T.; Janette, H.; Terrence, H.A. 5-Acyl-3-substituted benzofuran-2(3H)-ones as potential antiinflammatory agents. J. Med. Chem. 1987, 30, 1663-1668.

57. Akbas, E.; Berber, I. Antibacterial and antifungal activities of new pyrazolo[3,4- $d]$ pyridazin derivatives. Eur. J. Med. Chem. 2005, 40, 401-405.

58. Rostom, S.A.F.; Shalaby, M.A.; El-Demellawy, M.A. Polysubstituted pyrazoles, part 5. Synthesis of new 1-(4-chlorophenyl)-4-hydroxy-1H-pyrazole-3-carboxylic acid hydrazide analogs and some derived ring systems. A novel class of potential antitumor and anti-HVC agents. Eur. J. Med. Chem. 2003, 38, 959-974.

59. Manna, K.; Agrawal, Y.K. Microwave assisted synthesis of new indophenazine 1,3,5-trisubstruted pyrazoline derivatives of benzofuran and their antimicrobial activity. Bioorg. Med. Chem. Lett. 2009, 19, 2688-2692.

60. Weiss, U. Hepatitis C. Nature 2005, 436, 929-978.

61. Feld, J.J.; Hoofnagle, J.H. Mechanism of action of interferon and ribavirin in treatment of hepatitis C. Nature 2005, 436, 967-972.

62. Zhu, R.; Wang, M.; Xia, Y.; Qu, F.; Neyts, J.; Peng, L. Arylethynyltriazole acyclonucleosides inhibit hepatitis C virus replication. Bioorg. Med. Chem. Lett. 2008, 18, 3321-3327.

63. Zhu, R.; Qu, F.; Quéléver, G.; Peng, L. Direct synthesis of 5-aryltriazole acyclonucleosides via Suzuki coupling in aqueous solution. Tetrahedron Lett. 2007, 48, 2389-2393.

64. van Compernolle, S.E.; Wiznycia, A.V.; Rush, J.R.; Dhanasekaran, M.; Baures, P.W.; Todd, S.C. Small molecule inhibition of hepatitis $\mathrm{C}$ virus E2 binding to CD81. Virology 2003, 314, 371-380.

65. Holzer, M.; Ziegler, S.; Albrecht, B.; Kronenberger, B.; Kaul, A.; Bartenschlager, R.; Kattner, L.; Klein, C.D.; Hartmann, R.W. Identification of terfenadine as an inhibitor of human 
CD81-receptor HCV-E2 interaction: Synthesis and structure optimization. Molecules 2008, 13, 1081-1110.

66. Ziegler, S.; Kronenberger, B.; Albrecht, B.A.-M.; Kaul, A.; Gamer, A.-L.; Klein, C.D.; Hartmann, R.W. Development and evaluation of a FACS-based medium-throughput assay for HCV entry inhibitors. J. Biomol. Screen. 2009, 14, 620-626.

67. Carr, A.; Clyde, R. Piperidinderivate. D.E. Patent 25.06.770, 1975.

68. de Clercq, E. Recent highlights in the development of new antiviral drugs. Curr. Opin. Microb. 2005, 8, 552-560.

69. Richman, D.D. Antiviral drug resistance. Antivir. Res. 2006, 71, 117-121.

70. Smejkal, J.; Sorm, F. Nucleic acid components and their analogues. 53. Preparation of 1-(2-deoxy- $\beta$ 1-ribofuranosyl)thymine (1-thymidine). Collect. Czech. Chem. Commun. 1964, 29, 2809-2813.

71. Maury, G. The enantioselectivity of enzymes involved in current antiviral therapy using nucleoside analogues: A new strategy? Antivir. Chem. Chemother. 2000, 11, 165-190.

72. Focher, F.; Spadari, S.; Maga, G. Antivirals at the mirror: The lack of stereospecificity of some viral and human enzymes offers novel opportunities in antiviral drug development. Curr. Drug Targets Infect. Disord. 2003, 3, 41-53.

73. Beach, J.W.; Jeong, L.S.; Alves, A.J.; Pohl, D.; Kim, H.O.; Chang, C.-N.; Doong, S.-L.; Schinazi, R.F.; Cheng, Y.-C.; Chu, C.K. Synthesis of enantiomerically pure (2'R,5'S)-(-)-1-[2(hydroxymethyl)oxathiolan-5-yl]cytosine as a potent antiviral agent against hepatitis B virus (HBV) and human immunodeficiency virus (HIV). J. Org. Chem. 1992, 57, 2217-2219.

74. Cameron, J.M.; Collins, P.; Daniel, M.; Storer, R.; Wilcox, P. Lamivudine. Drugs Future 1993, 18, 319-323.

75. Schinazi, R.F.; Lloyd, R.M., Jr.; Nguyen, M.-H.; Cannon, D.L.; McMillan, A.; Ilksoy, N.; Chu, C.K.; Liotta, D.C.; Bazmi, H.Z.; Mellors, J.W. Characterization of human immunodeficiency viruses resistant to oxathiolane-cytosine nucleosides. Antimicrob. Agents Chemother. 1993, 37, 875-881.

76. Zhang, H.-W.; Detorio, M.; Herman, B.D.; Solomon, S.; Bassit, L.; Nettles, J.H.; Obikhod, A.; Tao, S.-J.; Mellors, J.W.; Sluis-Cremer, N.; et al. Synthesis, antiviral activity, cytotoxicity and cellular pharmacology of 1-3'-azido-2',3'-dideoxypurine nucleosides. Eur. J. Med. Chem. 2011, 46, 3832-3844.

77. Bookser, B.C.; Raffaele, N.B. High-throughput five minute microwave accelerated glycosylation approach to the synthesis of nucleoside libraries. J. Org. Chem. 2007, 72, 173-179.

78. Pepin, J.; Meda, H.A. The epidemiology and control of human African trypanosomiasis. Adv. Parasitol. 2001, 49, 71-132.

79. Barrett, M.P.; Burchmore, R.J.S.; Stich, A.; Lazzari, J.O.; Frasch, A.C.; Cazzulo, J.J.; Krishna, S. The trypanosomiases. Lancet 2003, 362, 1469-1480.

80. Rodgers, J.J. Human African trypanosomiasis, chemotherapy and CNS disease. J. Neuroimmunol. 2009, 211, 16-22.

81. Kennedy, P.G.E. The continuing problem of human African trypanosomiasis (sleeping sickness). Ann. Neurol. 2008, 64, 116-126.

82. Denise, H.; Barrett, M.P. Uptake and mode of action of drugs used against sleeping sickness. Biochem. Pharmacol. 2001, 61, 1-5. 
83. Knockaert, M.; Wieking, K.; Schmitt, S.; Leost, M.; Grant, K.M.; Mottram, J.C.; Kunick, C.; Meijer, L. Intracellular targets of paullones: Identification following affinity purification on immobilized inhibitor. J. Biol. Chem. 2002, 277, 25493-25501.

84. Clark, R.L.; Carter, K.C.; Mullen, A.B.; Coxon, G.D.; Owusu-Dapaah, G.; McFarlane, E.; Duong Thi, M.D.; Mackay, S.P. Identification of the benzodiazepines as a new class of antileishmanial agent. Bioorg. Med. Chem. Lett. 2007, 17, 624-627.

85. Spencer, J.; Rathnam, R.P.; Harvey, A.L.; Clements, C.J.; Clark, R.L.; Barrett, M.P.; Wong, P.E.; Male, L.; Coles, S.J.; MacKay, S.P. Synthesis and biological evaluation of 1,4-benzodiazepin-2-ones with antitrypanosomal activity. Bioorg. Med. Chem. 2011, 19, 1802-1815.

86. Spencer, J.; Anjum, N.; Patel, H.; Rathnam, R.P.; Verma, J. Molybdenum hexacarbonyl and DBU reduction of nitro compounds under microwave irradiation. Synlett 2007, 13, 2557-2558.

87. Spencer, J.; Rathnam, R.P.; Patel, H.; Anjum, N. Microwave mediated reduction of heterocycle and fluorine containing nitroaromatics with $\mathrm{Mo}(\mathrm{CO}) 6$ and DBU. Tetrahedron 2008, 64, 10195-10200.

88. World Malaria Report 2008; World Health Organization: Geneva, Switzerland, 2008.

89. White, N.J.J. Antimalarial drug resistance. Clin. Invest. 2004, 113, 1084-1092.

90. Orrling, K.M.; Marzahn, M.R.; Gutiérrez-de-Terán, H.; Åqvist, J.; Dunn, B.M.; Larhed, M. $\alpha$-Substituted norstatines as the transition-state mimic in inhibitors of multiple digestive vacuole malaria aspartic proteases. Bioorg. Med. Chem. 2009, 17, 5933-5949.

91. Ekegren, J.K.; Gising, J.; Wallberg, H.; Larhed, M.; Samuelsson, B.; Hallberg, A. Variations of the P2 group in HIV-1 protease inhibitors containing a tertiary alcohol in the transition-state mimicking scaffold. Org. Biomol. Chem. 2006, 4, 3040-3043.

92. Chappuis, F.; Sundar, S.; Hailu, A.; Ghalib, H.; Rijal, S.; Peeling, R.W.; Alvar, J.; Boelaert, M. Visceral leishmaniasis: What are the needs for diagnosis, treatment and control? Nat. Rev. Microbiol. 2007, 5, S7-S16.

93. Sands, M.; Kron, M.A.; Brown, R.B. Pentamidine: A review. Rev. Infect. Dis. 1985, 7, 625-634.

94. Bray, P.G.; Barrett, M.P.; Ward, S.A.; de Koning, H.P. Pentamidine uptake and resistance in pathogenic protozoa: Past, present and future. Trends Parasitol. 2003, 19, 232-239.

95. Berman, J.D. Human leishmaniasis: Clinical, diagnostic, and chemotherapeutic developments in the last 10 years. Clin. Infect. Dis. 1997, 24, 684-703.

96. Castro, M. Treatment and prophylaxis of pneumocystis carinii pneumonia. Semin. Respir. Infect. 1998, 13, 296-303.

97. Burri, C. Chemotherapy against human African trypanosomiasis: Is there a road to success? Parasitology 2010, 137, 1987-1994.

98. Oliveira, L.F.; Schubach, A.O.; Martins, M.M.; Passos, S.L.; Oliveira, R.V.; Marzochi, M.C.; Andrade, C.A. Systematic review of the adverse effects of cutaneous leishmaniasis treatment in the new world. Acta Trop. 2011, 118, 87-96.

99. Fairlamb, A.H. Chemotherapy of human African trypanosomiasis: Current and future prospects. Trends Parasitol. 2003, 19, 488-494.

100. Zolek, T.; Maciejewska, D. Theoretical models of pentamidine analogs activity based on their DNA minor groove complexes. Eur. J. Med. Chem. 2010, 45, 1991-1999. 
101. Moreno, T.; Pous, J.; Subirana, J.A.; Campos, J.L. Coiled-coil conformation of a pentamidine-DNA complex. Acta Crystallorgr. D Biol. Crystallogr. 2010, 66, 251-257.

102. Thuita, J.K.; Karanja, S.M.; Wenzler, T.; Mdachi, R.E.; Ngotho, J.M.; Kagira, J.M.; Tidwell, R.; Brun, R. Efficacy of the diamidine DB75 and its prodrug DB289, against murine models of human African trypanosomiasis. Acta Trop. 2008, 108, 6-10.

103. Paloque, L.; Bouhlel, A.; Curti, C.; Dumtre, A.; Verhaeghe, P.; Azas, N.; Vanelle, P. Synthesis and evaluation of monoamidoxime derivatives: Toward new antileishmanial compounds. Eur. J. Med. Chem. 2011, 46, 2984-2991.

104. Knol - A unit of knowledge. Available online: http://knol.google.com/k/krishan-maggon/globalbrain-drugs-market-review-2008/3fy5eowy8suq3/1\# (accessed on 15 July 2011).

105. Korzh, M. The efficacy and safety of zolpidem over 12 months in patient with low back pain and chronic insomnia. Sleep Med. 2007, 8, 578.

106. Yogeeswari, P.; Menon, N.; Semwal, A.; Arjun, M.; Sriram, D. Discovery of mole cules for the treatment of neuropathic pain: Synthesis, antiallodynic and antihyperalgesic activities of 5-(4-nitrophenyl0furoic-2-acid hydrazones. Eur. J. Med. Chem. 2011, 46, 2964-2970.

107. Kummerle, A.E.; Vieira, M.M.; Schmitt, M.; Miranda, A.L.P.; Fraga, C.A.M.; Bourguignon, J.-J.; Barreiro, E.J. Design, synthesis and analgesic properties of novel conformationally-restricted N-acylhydrazones. Eur. J. Med. Chem. 2009, 19, 4963-4966.

108. Menegatti, R.; Silva, G.M.S.; Zapata-Sudo, G.; Raimundo, J.M.; Sudo, R.T.; Barreiro, E.J.; Fraga, C.A.M. Design, synthesis and pharmacological evaluation of new neuroactive pyrazolo[3,4-b]pyrrolo[3,4- $d]$ pyridine derivatives with in vivo hypnotic and analgesic profile. Bioorg. Med. Chem. 2006, 14, 632-640.

109. Mendes, T.C.F.; Raimundo, J.M.; Nascimento-Junior, N.M.; Fraga, C.A.M.; Barreiro, E.J.; Sudo, R.T.; Zapata-Sudo, G. Sedation and antinociception induced by a new pyrazolo[3,4$b]$ pyrrolo[3,4- $d$ ]pyridine derivative (LASSBio-873) is modulated by activation of muscarinic receptors. Pharmacol. Biochem. Behav. 2009, 94, 70-74.

110. Tsuji, R.; Isobe, N.; Kawasaki, H. Mechanism of prolongation of pentobarbital-induced sleeping time by empenthrin in mice. Toxicology 1996, 108, 185-190.

111. Mora, S.; Diaz-Veliz, G.; Lungentrass, H.; García-Gonzáles, M.; Coto-Morales, T.; Poletti, C.; de Lima, T.C.; Herrera-Ruiz, M.; Tortoriello, J. Central nervous system activity of the hydroalcocholic extract of Casimiroa edulis in rat and mice . J. Ethnopharmacol. 2005, 97, 191-197.

112. Dundee, J.W.; Halliday, N.J.; Harper, K.W.; Brogden, R.N. Midazolan a review of its pharmacological properties and therapeutic use. Drugs 1984, 28, 519-543.

113. Kuraishi, Y.; Harada, Y.; Aratani, S.; Satoh, M.; Takagi, H. Separate involvement of the spinal noradrenergic and serotoninergic system in morphine analgesia: The differences in mechanical and thermal algesic tests. Brain Res. 1983, 273, 245-252.

114. Nascimento-Júnior, N.M.; Mendes, T.C.F.; Leal, D.M.; Corrêa, C.M.N.; Sudo, R.T.; Zapata-Sudo, G.; Bareiro, E.J.; Fraga, C.A.M. Microwave assisted-synthesis and structure-activity relatioships of neuroactive pyrazolo[3,4-b]pyrrolo[3,4- $d]$ pyridine derivatives. Bioorg. Med. Chem. Lett. 2010, 20, 74-77. 
115. Díaz-Ortiz, A.; Carrilo, J.R.; Gómez-Escalonilla, M.J.; de La Hoz, A.; Moreno, A.; Prieto, P. First diels-alder reaction of pyrazolil imides under microwave irradiation. Synlett 1998, 10, 1069-1070.

116. Díaz-Ortiz, A.; de La Hoz, A.; Langa, F. Microwave irradiation in free-solvent conditions: An eco-friendly methodology to prepare indazoles, pyrazolopyridines and bipyrazoles by cycloaddition reactions. Green Chem. 2000, 2, 165-172.

117. Díaz-Ortiz, A.; Carrilo, J.R.; Cossio, F.P.; Gómez-Escalonila, M.J.; de La Hoz, A.; Moreno, A.; Prieto, P. Synthesis of pyrazolo[3,4-b]pyridines by cycloaddition reactions under microwave irradiation. Tetrahedron 2000, 56, 1569-1577.

Sample Availability: Samples of the compounds are not available.

(C) 2011 by the authors; licensee MDPI, Basel, Switzerland. This article is an open access article distributed under the terms and conditions of the Creative Commons Attribution license (http://creativecommons.org/licenses/by/3.0/). 